FEDERAL RESERVE BANK OF SAN FRANCISCO

WORKING PAPER SERIES

\title{
Time-Varying U.S. Inflation Dynamics and the New Keynesian Phillips Curve
}

\author{
Kevin J. Lansing \\ Federal Reserve Bank of San Francisco
}

August 2008

Working Paper 2006-15

http://www.frbsf.org/publications/economics/papers/2006/wp06-15bk.pdf

The views in this paper are solely the responsibility of the authors and should not be interpreted as reflecting the views of the Federal Reserve Bank of San Francisco or the Board of Governors of the Federal Reserve System. 


\title{
Time-Varying U.S. Inflation Dynamics and the New Keynesian Phillips Curve*
}

\author{
Kevin J. Lansing ${ }^{\dagger}$ \\ Federal Reserve Bank of San Francisco
}

August 12, 2008

\begin{abstract}
This paper introduces a form of boundedly-rational inflation expectations in the New Keynesian Phillips curve. The representative agent is assumed to behave as an econometrician, employing a time series model for inflation that allows for both permanent and temporary shocks. The near-unity coefficient on expected inflation in the Phillips curve causes the agent's perception of a unit root in inflation to become close to self-fulfilling. In a "consistent expectations equilibrium," the value of the Kalman gain parameter in the agent's forecast rule is pinned down using the observed autocorrelation of inflation changes. The forecast errors observed by the agent are close to white noise, making it difficult for the agent to detect a misspecification of the forecast rule. I show that this simple model of inflation expectations can generate time-varying persistence and volatility that is broadly similar to that observed in long-run U.S. data. Model-based values for expected inflation track well with movements in survey-based measures of U.S. expected inflation. In numerical simulations, the model can generate pronounced low-frequency swings in the level of inflation that are driven solely by expectational feedback, not by changes in monetary policy.
\end{abstract}

Keywords: Inflation Expectations, Phillips Curve, Time-Varying Persistence 83 Volatility.

JEL Classification: E31, E37.

${ }^{*}$ Forthcoming, Review of Economic Dynamics. For helpful comments and suggestions, I thank Marc Giannoni, Cars Hommes, John Roberts, Karl Whelan, seminar participants at the University of Amsterdam, Norges Bank, and other economic conferences. I also thank an anonymous referee and an associate editor for thoughtful suggestions that improved the paper.

† Research Department, Federal Reserve Bank of San Francisco, P.O. Box 7702, San Francisco, CA 94120-7702, (415) 974-2393, FAX: (415) 977-4031, email: kevin.j.lansing@sf.frb.org, homepage: www.frbsf.org/economics/economists/klansing.html 


\section{Introduction}

\subsection{Overview}

The New Keynesian Phillips Curve (NKPC) is derived most straightforwardly from Calvo's (1983) model of sticky price adjustment. Numerous researchers have criticized the fullyrational NKPC on grounds that a reasonably parameterized version fails to capture important features of post-World War II U.S. data, namely, high levels of inflation persistence and the delayed and gradual response of inflation to unanticipated monetary policy shocks. ${ }^{1}$ Other researchers have argued that the appropriate inclusion of exogenous stochastic driving variables that reflect changes in monetary policy can improve the empirical performance of the fullyrational NKPC. ${ }^{2}$

This paper introduces a form of boundedly-rational inflation expectations in the NKPC for an economy where all monetary policy variables are held constant. The representative agent is assumed to behave as an econometrician, employing a time series model for inflation that allows for both permanent and temporary shocks. The agent's perceived optimal forecast rule is defined by the Kalman filter. I show that the perceived optimal value of the Kalman gain parameter assigned to the last observed inflation rate is given by the fixed point of a nonlinear map that relates the gain parameter to the observed autocorrelation of inflation changes. By computing the value of the autocorrelation coefficient, the agent can identify the "signal-tonoise ratio," which measures the relative variances of the perceived permanent and temporary shocks to inflation. A higher signal-to-noise ratio calls for a higher Kalman gain parameter which, in turn, places more weight on recent inflation data in the agent's forecast rule. In a "consistent expectations equilibrium," the forecast errors observed by the agent are close to white noise, making it difficult for the agent to detect a misspecification of the forecast rule. ${ }^{3}$ Moreover, from the individual agent's perspective, switching to a fundamentals-based inflation forecast (which makes use of the output gap or real marginal cost) would appear to reduce forecast accuracy, so there is no incentive to switch. Intuitively, the equilibrium exploits the fact that expected inflation enters the NKPC with a near-unity coefficient. This feature causes the agent's perception of a unit root in inflation to become close to self-fulfilling.

The model allows for either a constant gain or a variable gain, depending on the length of the sample period used by the agent to identify the signal-to-noise ratio from observed inflation data. As the sample period becomes infinitely long, the equilibrium yields a constant gain. A rolling sample period yields a variable gain. From the agent's perspective, the use of a variable Kalman gain is justified by perceived movements in the signal-to-noise ratio.

\footnotetext{
${ }^{1}$ See, for example, Roberts (1997, 2005), Fuhrer (1997, 2006), Mankiw (2001), Estrella and Fuhrer (2002), and Rudd and Whelan (2005a, 2007).

${ }^{2}$ See, for example, Kozicki and Tinsley (2002, 2005), Ireland (2007), and Cogley and Sbordone (2008).

${ }^{3}$ This boundedly-rational equilibrium concept was developed by Hommes and Sorger (1998). A closelyrelated concept is the "restricted perceptions equilibrium" described by Evans and Honkopohja (2001, Chapter $13)$.
} 
In the variable-gain version of the model, the nonlinear law of motion for inflation generates time-varying persistence and volatility that is broadly similar to that observed in long-run U.S. data.

The model's methodology for identifying the signal-to-noise ratio can be applied directly to U.S. inflation data. The identified U.S. signal-to-noise ratio exhibits an upward drift during the 1970s, followed by downward drift from the mid-1990s onwards. The downward drifting ratio over the last decade indicates a reduced likelihood of a permanent shift, either upwards or downwards, in the Fed's inflation target. This evidence is consistent with the idea of "well-anchored inflation expectations" in describing the recent environment (see, for example, Williams 2006). The identified signal-to-noise ratio in U.S. data might therefore be viewed as an inverse measure of the Fed's credibility for maintaining a constant inflation target. In the consistent expectations framework, the agent's inflation forecast is an exponentially-weighted moving average of past observed inflation rates. This feature tracks well with movements in survey-based measures of U.S. expected inflation.

The driving variable for inflation in the model can be interpreted as either the output gap or real marginal cost. Monetary policy enters the model implicitly through two channels: (i) the steady-state inflation rate around which the NKPC is log-linearized - maintained here at zero, or (ii) the parameters that govern the exogenous stochastic process for the driving variable. All policy-dependent parameters are held constant throughout the analysis. Interestingly, the model can generate pronounced low-frequency swings in the level of inflation that are driven solely by expectational feedback, not by changes in monetary policy. The low-frequency swings derive from the near-random walk behavior of inflation under consistent expectations. From the agent's perspective, the observed low-frequency swings justify the use of a forecast rule that allows for permanent shocks. This aspect of the model bears similarity to the "optimal misspecified beliefs" concept described by Sargent (1999, Chapter 6).

Klein (1978) and Barsky (1987) were among the first to call attention to the dramatic changes in inflation persistence in long-run U.S. data. Barsky (p. 3) noted that "Inflation evolved from essentially a white noise process in the pre-World War I years, to a highly persistent, non-stationary ARIMA process in the post-1960 period." More recently, Cogley and Sargent $(2002,2005)$ employ vector autoregressions that allow for drifting coefficients and stochastic volatility to document the evolving nature of U.S. inflation dynamics in postWorld War II data. Their methodology identifies a positive correlation between measures of persistence, volatility, and the level of inflation in post-World War II data. Simple 20-year rolling summary statistics confirm these basic findings. As a caveat, it should be noted that findings of time-varying inflation persistence in recent data are not universal. Pivetta and Reis (2007) argue that the wide confidence intervals around measures of inflation persistence do not allow one to reject the hypothesis of no change in persistence since 1965. These authors do find robust evidence of a change in inflation volatility, however.

Shifts in monetary policy are one candidate for explaining changes in inflation dynamics. 
Both Klein (1978) and Barsky (1987) attribute the change in inflation persistence after World War I to the abandonment of the classical gold standard. A gold standard can be viewed as a price-level targeting regime. Under an inflation-targeting regime, shifts in the central bank's inflation target (which determines the trend inflation rate) can distort standard measures of persistence and volatility. For this reason, measures of persistence and volatility should be conditioned on an estimate of trend inflation. ${ }^{4}$ In computing the 20-year rolling summary statistics, I control for shifts in trend inflation by first extracting the low-frequency component of U.S. inflation. Detrended inflation continues to exhibit time-varying patterns of persistence and volatility, even during periods of seemingly-unchanged monetary policy, such as the sample period since 1995. Such observations suggest that U.S. inflation is driven by a number of different nonlinearities, not just those attributable to policy regime shifts.

\subsection{Related Literature}

The consideration of boundedly-rational inflation expectations is motivated by empirical evidence. Survey-based measures of U.S. inflation expectations tend to systematically underpredict actual inflation in the sample period prior to October 1979 and systematically overpredict it thereafter. Rational expectations would not give rise to a sustained sequence of one-sided forecast errors. Roberts (1997), Carroll (2003), Mankiw, Reis, and Wolfers (2004), and Branch (2004) all find evidence that survey-based measures of U.S. inflation expectations do not make the most efficient use of available information.

The boundedly-rational form of expectations used here is similar to that explored by Evans and Ramey (2006) in the context of the Lucas (1973) monetary policy model. In their framework, the value of the gain parameter is pinned down using a Nash equilibrium concept. ${ }^{5}$

An empirical study by Ball (2000) allows for a switch between two forms of "near-rational" forecast rules to help account for the dramatic change in U.S. inflation persistence identified by Klein (1978) and Barsky (1987). In Ball's framework, the switch between forecast rules is imposed within the model; it is not an endogenous response to an actual or perceived shift in fundamentals.

Orphanides and Williams (2005) and Milani (2005) introduce inflation persistence in the form of constant-gain learning in models where the underlying fundamentals do not shift. The representative agent's perceived law of motion for inflation is an $\operatorname{AR}(1)$ process with parameters that are perpetually re-estimated using recent data. Unlike here, the constant gain used in the learning algorithm is a free parameter that is calibrated rather than endogenized within the model itself. In the learning model of Erceg and Levin (2003), the value of the gain parameter is estimated by minimizing the squared deviations between the model's inflation expectations

\footnotetext{
${ }^{4}$ This point has been emphasized by Kozicki and Tinsley (2002), Levin and Piger (2004), and Marques (2004), among others.

${ }^{5}$ The use of a Nash equilibrium to determine the gain was first demonstrated by Evans and Honkopohja (1993).
} 
and survey-based U.S. inflation expectations.

Research that examines the links between exogenous policy rule shifts and inflation dynamics includes Boivin and Giannoni (2006), Roberts (2006), and Cecchetti et al. (2007). Papers by Kozicki and Tinsley (2002, 2005), Ireland (2007), and Cogley and Sbordone (2008) show that the empirical performance of the fully-rational NKPC can be improved by introducing a highly persistent, exogenous stochastic process for the central bank's inflation target. It remains unclear, however, why an optimizing central bank would wish to adopt such a process for the inflation target. ${ }^{6}$ Moreover, in order to account for the time-varying dynamic properties of detrended U.S. inflation, these models would need to incorporate exogenous shifts in other parameters of the central bank's policy rule. The approach taken here is to develop a model that abstracts from actual shifts in the central bank's inflation target or any other aspect of monetary policy. The model simulations are compared to U.S. data on the basis of detrended inflation behavior - analogous to the methodology employed in the real business cycle literature. The main message of the paper is that expectational feedback can be an important driving force for inflation dynamics.

\section{Time-Varying Persistence and Volatility in U.S. Inflation}

Figure 1 provides evidence of time-varying persistence and volatility in U.S. inflation data. The left-side panels plot the data and 20-year rolling summary statistics for CPI inflation from 1871.Q1 to 2004.Q4. The right-side panels plot the same information for GDP price inflation from 1949.Q1 to 2004.Q4. ${ }^{7}$ The 20-year rolling summary statistics are computed for both the raw and detrended inflation series. Detrending is a way to control for shifts in the central bank's inflation target that may have occurred over time. ${ }^{8}$

[Figure 1 about here]

Panel 1a illustrates the dramatic difference in the behavior of pre- and post-World War I inflation noted by Klein (1978) and Barsky (1987). The simple measure of persistence used

\footnotetext{
${ }^{6}$ In Ireland (2007), the law of motion for the inflation target is a geometric random walk. Exogenous shocks can permanently shift the target by amounts that are determined by exogenous monetary policy coefficients.

${ }^{7}$ The annualized 1-quarter inflation rate is given by $4 \log \left(P_{t} / P_{t-1}\right)$, where $P_{t}$ is the relevant price index. The quarterly CPI data were constructed by averaging monthly CPI data obtained from Robert Shiller's website: http://www.econ.yale.edu/ ${ }^{\sim}$ shiller/data/ie_data.htm. Shiller's data employs the CPI-U (Consumer Price Index-All Urban Consumers) published by the U.S. Bureau of Labor Statistics from 1913 onward. For prior years, Shiller's price index is constructed by splicing to monthly price data obtained from Warren and Pearson (1935, Table 1, pp. 11-14). Data on the quarterly GDP price index is from http://research.stlouisfed.org/fred2/series/GDPCTPI.

${ }^{8}$ Throughout the paper, the inflation trend is defined as the low-frequency component of the data (fluctuations longer than 32 quarters) extracted using the band pass filter approximation of Christiano and Fitzgerald (2003). Similar results are obtained if the data are detrended using the Hodrick-Prescott filter with a smoothing parameter of 1600 .
} 
here is the 20-year rolling autocorrelation coefficient. ${ }^{9}$ Persistence hovers close to zero during the pre-World War I era but then starts to increase around the year 1915 (panel 1c). There are some notable variations in persistence over the ensuing decades, followed by a sharp drop in the rolling autocorrelation towards the end of the sample. The end-of-sample drop in persistence is also evident in GDP price inflation (panel 1d).

Volatility is measured by the 20-year rolling standard deviation. The volatility of CPI inflation declines from the early part of the sample until about the year 1970. Volatility then traces out a hump-shaped pattern over the next 35 years (panel 1e). The volatility of GDP price inflation exhibits a similar hump-shaped pattern (panel 1f).

Measures of persistence and volatility are generally lower in the detrended data, but the basic patterns resemble those in the raw data. Notice that these measures have declined during the sample period since 1995. During the post-World War II sample period, the most striking feature is the similarity in the patterns observed for the rolling persistence, rolling volatility, and rolling mean of U.S. inflation. This result confirms the findings of Cogley and Sargent $(2002,2005)$ who use forward-looking Bayesian methods to identify a strong positive correlation among summary statistics computed for post-World War II inflation data. Interestingly, one can identify some roughly similar patterns of comovement in the rolling summary statistics for the earlier inflation data plotted on the left-side of Figure 1. Overall, the time-varying features of the data suggest the presence of nonlinearities in the law of motion for U.S. inflation. In later sections of the paper, a quantitative summary of U.S. inflation dynamics will be compared with the results of model simulations.

\section{The New Keynesian Phillips Curve}

The starting point for the analysis is the standard NKPC:

$$
\pi_{t}=\beta \widehat{E}_{t} \pi_{t+1}+\gamma y_{t}+\varepsilon_{t}, \quad \beta \in[0,1), \quad \gamma>0, \quad \varepsilon_{t} \sim N\left(0, \sigma_{\varepsilon}^{2}\right),
$$

where $\pi_{t}$ is the inflation rate defined as the log difference of the price level, $\beta$ is the representative agent's subjective time discount factor, $y_{t}$ is a stationary driving variable, and $\varepsilon_{t}$ is an iid markup shock that is often motivated by the presence of a variable tax rate. ${ }^{10}$ The symbol $\widehat{E}_{t}$ represents the agent's subjective expectation conditioned on information available at time $t$. Under rational expectations, $\widehat{E}_{t}$ corresponds to the mathematical expectation operator $E_{t}$ evaluated using the objective distributions of the driving variable and the markup shock.

The driving variable can be interpreted as either the output gap (often measured by detrended real GDP) or the representative firm's real marginal cost (often measured by labor's

\footnotetext{
${ }^{9}$ Another commonly-used measure of persistence is the sum of the autoregressive coefficients in a univariate regression. In the case of an $\operatorname{AR}(2)$ with coefficients $\theta_{1}$ and $\theta_{2}$, we have $\operatorname{Corr}\left(\pi_{t}, \pi_{t-1}\right)=\theta_{1} /\left(1-\theta_{2}\right)$. Both measures of persistence are increasing in $\theta_{1}$ and $\theta_{2}$.

${ }^{10}$ The rational expectations version of equation (1) is derived by Woodford (2003, Chapter 3 ).
} 
share of income). Since $y_{t}$ is taken here to be exogenous, none of the paper's theoretical results depend on which interpretation is chosen. ${ }^{11}$ The law of motion for the driving variable is

$$
y_{t}=\rho y_{t-1}+u_{t} \quad \rho \in[0,1), u_{t} \sim N\left(0, \sigma_{u}^{2}\right),
$$

where $u_{t}$ is an iid demand shock that is uncorrelated with the markup shock.

Monetary policy enters implicitly in the model through two potential channels. The first is the steady-state inflation rate that is used when deriving equation (1) using a log-linear approximation. The second is the values of $\rho$ and $\sigma_{u}^{2}$, which can be interpreted as reducedform parameters that depend in a complicated way on the central bank's policy rule. ${ }^{12}$ For both of the equilibrium concepts described below, the inflation process remains stationary around the zero-inflation steady state. The parameters $\rho$ and $\sigma_{u}^{2}$ are held constant throughout the analysis.

\subsection{Rational Expectations}

Under rational expectations, the inflation rate at time $t$ is uniquely pinned down by the agent's forecast of discounted future values of the driving variable, plus the current realization of the markup shock. To derive the unique rational expectations solution, first replace $\widehat{E}_{t}$ in equation (1) with $E_{t}$. Equation (1) can then be iterated forward to substitute out $\pi_{t+1+k}$ for $k=0,1,2, \ldots$ Applying the law of iterated expectations and imposing a transversality condition yields the following present-value inflation equation

$$
\pi_{t}^{\mathrm{re}}=\gamma E_{t}\left\{y_{t}+\beta y_{t+1}+\beta^{2} y_{t+2}+\ldots\right\}+\varepsilon_{t},
$$

where $\pi_{t}^{\text {re }}$ represents the equilibrium inflation rate under rational expectations. Given that $u_{t}$ is iid, equation (3) admits the following closed-form solution:

$$
\pi_{t}^{\mathrm{re}}=\left[\frac{\gamma}{1-\rho \beta}\right] y_{t}+\varepsilon_{t}
$$

which shows that the rational (or fundamentals-based) inflation rate inherits its stochastic properties from both the autoregressive driving variable and the white-noise markup shock.

\footnotetext{
${ }^{11}$ In empirical applications, the choice of driving variable is quite important. Detrended real GDP is procyclical whereas labor's share of income is countercyclical. See Rudd and Whelan (2005b).

${ }^{12} \mathrm{~A}$ simple example illustrates the point. Suppose that the IS equation is given by $y_{t}=$ $\beta\left[\theta \widehat{E}_{t} y_{t+1}+(1-\theta) y_{t-1}\right]-\alpha_{r}\left(i_{i}-\widehat{E}_{t} \pi_{t+1}-\bar{r}\right)+\varsigma_{t}$, and the central bank's policy rule is given by $i_{t}=$ $\bar{r}+g_{\pi} \widehat{E}_{t} \pi_{t+1}+g_{y} \widehat{E}_{t} y_{t+1}$, where $i_{t}$ is the policy instrument, $\bar{r}$ is the steady-state real rate, and $\varsigma_{t}$ is an iid demand shock. Then, under rational expectations $\left(\widehat{E}_{t}=E_{t}\right)$, it can be shown that the equilibrium IS equation is exactly the form of (2), where $\rho$ and $\sigma_{u}^{2}$ both depend on $g_{\pi}$ and $g_{y}$. If expectations are only boundedly-rational, then (2) is still likely to be reasonable approximation of an empirically-plausible equilibrium IS equation.
} 
Equations (2) and (4) yield the following expressions for the unconditional moments:

$$
\begin{aligned}
\operatorname{Var}\left(\pi_{t}^{\mathrm{re}}\right) & =\left[\frac{\gamma^{2}}{(1-\rho \beta)^{2}\left(1-\rho^{2}\right)}\right] \sigma_{u}^{2}+\sigma_{\varepsilon}^{2}, \\
\operatorname{Corr}\left(\pi_{t}^{\mathrm{re}}, \pi_{t-1}^{\mathrm{re}}\right) & =\frac{\gamma^{2} \rho}{\gamma^{2}+(1-\rho \beta)^{2}\left(1-\rho^{2}\right)\left(\sigma_{\varepsilon}^{2} / \sigma_{u}^{2}\right)}, \\
\operatorname{Corr}\left(\Delta \pi_{t}^{\mathrm{re}}, \Delta \pi_{t-1}^{\mathrm{re}}\right) & =-\frac{1}{2}\left[\frac{\gamma^{2}(1-\rho)+(1-\rho \beta)^{2}(1+\rho)\left(\sigma_{\varepsilon}^{2} / \sigma_{u}^{2}\right)}{\gamma^{2}+(1-\rho \beta)^{2}(1+\rho)\left(\sigma_{\varepsilon}^{2} / \sigma_{u}^{2}\right)}\right]
\end{aligned}
$$

where $\operatorname{Var}(\cdot)$ denotes the unconditional variance, $\operatorname{Corr}(\cdot, \cdot)$ is the unconditional correlation coefficient, and $\Delta \pi_{t}^{\mathrm{re}}=\pi_{t}^{\mathrm{re}}-\pi_{t-1}^{\mathrm{re}}$.

Equation (6) confirms the results of Fuhrer (2006) that small values for the Phillips curve slope parameter $\gamma$ combined with nontrivial values for the shock variance ratio $\sigma_{\varepsilon}^{2} / \sigma_{u}^{2}$ (the empirically plausible case) imply weak persistence of inflation under rational expectations - a result that conflicts sharply with post-World War II U.S. inflation data. Equation (7) predicts that the autocorrelation of inflation changes is negative - a robust feature of U.S. data. Small values for the Phillips curve slope parameter imply $\gamma^{2} \approx 0$, such that $\operatorname{Corr}\left(\Delta \pi_{t}^{\mathrm{re}}, \Delta \pi_{t-1}^{\mathrm{re}}\right) \approx$ -0.5. In the post-World War II sample period, the autocorrelation of changes in U.S. GDP price inflation is -0.34 .

From equation (4), the one-period-ahead rational forecast is given by

$$
E_{t} \pi_{t+1}^{\mathrm{re}}=\left[\frac{\rho \gamma}{1-\rho \beta}\right] y_{t}
$$

which shows that the fundamentals-based inflation forecast is perfectly correlated with movements in the driving variable. The forecast requires information about the current value of $y_{t}$, the policy-dependent parameter $\rho$, and the Phillips curve slope parameter $\gamma$. The discount factor $\beta$ is aspect of the agent's preferences and does not need to be observed.

\subsection{Consistent Expectations}

Equation (8) shows that rational forecasts derived from the standard NKPC are built on strong assumptions about the representative agent's information set. In actual forecasting applications, real-time difficulties in observing the driving variable, together with empirical instabilities in the parameters $\gamma$ and $\rho$, could lead to large and persistent forecast errors. Numerous studies have demonstrated that forecasts of U.S. inflation computed from empirical Phillips curve models can frequently underperform forecasts derived from simple univariate time series models, such as a random walk, AR, or ARMA. ${ }^{13}$ One would expect to encounter similar forecasting difficulties using the standard NKPC. These ideas motivate consideration of

\footnotetext{
${ }^{13}$ See, for example, Atkeson and Ohanian (2001), Orphanides and Van Norden (2005), Stock and Watson (2007), and Ang. et al. (2007).
} 
a univariate forecasting algorithm - one that requires very little computational or informational resources. A long history in macroeconomics suggests the following error-correction approach:

$$
\begin{aligned}
\widehat{E}_{t} \pi_{t+1} & =\widehat{E}_{t-1} \pi_{t}+\lambda\left(\pi_{t}-\widehat{E}_{t-1} \pi_{t}\right), \quad 0<\lambda \leq 1, \\
& =\lambda\left[\pi_{t}+(1-\lambda) \pi_{t-1}+(1-\lambda)^{2} \pi_{t-2}+\ldots\right],
\end{aligned}
$$

where $\pi_{t}-\widehat{E}_{t-1} \pi_{t}$ is the forecast error in period $t$. I assume that the agent's subjective forecast makes use of the contemporaneous realization $\pi_{t}$. This setup avoids the introduction of an extra lag of inflation that might be viewed as artificially influencing the resulting dynamics. ${ }^{14}$

Equation (9) implies that the agent's forecast at time $t$ is an exponentially-weighted moving average of past observed inflation rates. By comparison, the "sticky-information" model of Mankiw and Reis (2002) implies that the agent's forecast at time $t$ is based on an exponentiallyweighted moving average of past rational forecasts. ${ }^{15}$ Both arrangements bear symmetry to the Calvo (1983) sticky-price model where the equilibrium price level at time $t$ is an exponentiallyweighted moving average of past observed prices.

As originally shown by Muth (1960), the subjective forecast rule (9) will coincide with rational expectations when the forecast variable follows a simple and intuitive law of motion. That form is adopted here as the representative agent's perceived law of motion:

$$
\left[\begin{array}{l}
\pi_{t} \\
\bar{\pi}_{t}
\end{array}\right]=\left[\begin{array}{ll}
0 & 1 \\
0 & 1
\end{array}\right]\left[\begin{array}{l}
\pi_{t-1} \\
\bar{\pi}_{t-1}
\end{array}\right]+\left[\begin{array}{ll}
1 & 1 \\
0 & 1
\end{array}\right]\left[\begin{array}{c}
v_{t} \\
\eta_{t}
\end{array}\right], \quad \begin{aligned}
& v_{t} \sim N\left(0, \sigma_{v}^{2}\right) \\
& \eta_{t} \sim N\left(0, \sigma_{\eta}^{2}\right) \\
& \operatorname{Cov}\left(v_{t}, \eta_{t}\right)=0
\end{aligned}
$$

where $\bar{\pi}_{t}$ is the unobservable inflation trend, $v_{t}$ is a transitory shock that pushes $\pi_{t}$ away from trend, and $\eta_{t}$ is permanent shock (uncorrelated with $v_{t}$ ) that shifts the trend over time. The subjective forecast $\widehat{E}_{t} \pi_{t+1}$ is set equal to the Kalman filter estimate of $\bar{\pi}_{t}$. The random walk plus noise specification in (10) is equivalent to an ARMA $(1,1)$, as shown by Harvey (1993, p. 125). From a behavioral perspective, the representative agent can be viewed as an econometrician, employing a time series model identical to that used recently by Stock and Watson (2007). It need not be the case that the agent literally believes that inflation is governed by a unit root process. Rather, the agent may simply consider (10) to be versatile and parsimonious time series model for the purpose of constructing a real-time inflation forecast, say, because real-time data for the driving variable $y_{t}$ is subject to measurement error.

Some technical points are worth noting. First, although the perceived law of motion (10) allows for permanent shifts in the inflation trend, the equilibrium inflation process (to be defined below) remains stationary around the zero-inflation steady state. For this reason, I

\footnotetext{
${ }^{14} \mathrm{~A}$ lagged information assumption is often used in learning models to avoid simultaneity in the determination of the actual and expected values of the forecast variable. In the continuous time limit, the distinction between contemporaneous and lagged information disappears.

${ }^{15}$ The sticky-information model is discussed further in Section 7.
} 
abstract from changes in the functional form of the NKPC that arise when the Calvo pricing equation is log-linearized around a non-zero inflation rate, as shown by Ascari (2004) and Sahuc (2006). Second, I abstract from "long-horizon expectations" that arise in the NKPC when forward-looking agents employ subjective forecasts of future inflation, as discussed by Preston (2005). The perceived law of motion (10) implies $\widehat{E}_{t} \pi_{t+j}=\widehat{E}_{t} \pi_{t+1}$ for all future horizons $j=2,3,4 \ldots$ Equation (1) can therefore be viewed as a log-linear approximation of a more-complicated NKPC that explicitly incorporates long-horizon inflation expectations.

The agent's perceived optimal choice of $\lambda$ in equation (9) is determined by the Kalman filter, where the objective is to minimize the mean squared forecast error $E\left(\pi_{t+1}-\widehat{E}_{t} \pi_{t+1}\right)^{2}$. In steady-state, the unique solution for the perceived optimal gain parameter is

$$
\lambda=\frac{-\phi+\sqrt{\phi^{2}+4 \phi}}{2}
$$

where $\phi=\sigma_{\eta}^{2} / \sigma_{v}^{2}$ is the perceived signal-to-noise ratio. ${ }^{16}$ As $\phi \rightarrow \infty$, the gain parameter approaches 1 . From the agent's perspective, the shocks themselves $v_{t}$ and $\eta_{t}$ are unobservable, but the shock variances $\sigma_{\eta}^{2}$ and $\sigma_{v}^{2}$ can be inferred from the moments of inflation changes $\Delta \pi_{t}$, which are observable.

Proposition 1. If the representative agent's perceived law of motion is given by equation (10), then the perceived optimal value of the Kalman gain parameter $\lambda$ is uniquely pinned down by the autocorrelation of observed inflation changes, $\operatorname{Corr}\left(\Delta \pi_{t}, \Delta \pi_{t-1}\right)$.

Proof: From (10), we have $\Delta \pi_{t}=\eta_{t}+v_{t}-v_{t-1}$. Since $\eta_{t}$ and $v_{t}$ are perceived to be independent, we have $\operatorname{Cov}\left(\Delta \pi_{t}, \Delta \pi_{t-1}\right)=-\sigma_{v}^{2}$ and $\operatorname{Var}\left(\Delta \pi_{t}\right)=\sigma_{\eta}^{2}+2 \sigma_{v}^{2}$. Combining these two expressions and solving for the signal-to-noise ratio yields

$$
\phi=\frac{-1}{\operatorname{Corr}\left(\Delta \pi_{t}, \Delta \pi_{t-1}\right)}-2,
$$

where $\phi=\sigma_{\eta}^{2} / \sigma_{v}^{2}$ and $\operatorname{Corr}\left(\Delta \pi_{t}, \Delta \pi_{t-1}\right)=\operatorname{Cov}\left(\Delta \pi_{t}, \Delta \pi_{t-1}\right) / \operatorname{Var}\left(\Delta \pi_{t}\right)$. The above expression shows that $\operatorname{Corr}\left(\Delta \pi_{t}, \Delta \pi_{t-1}\right)$ uniquely pins down $\phi$ which, in turn, uniquely pins down $\lambda$ from equation (11).

Substituting the subjective forecast rule (9) into the NKPC equation (1) yields the following system of equations that define the actual law of motion for inflation:

$$
\left[\begin{array}{c}
\pi_{t} \\
\widehat{E}_{t} \pi_{t+1} \\
y_{t}
\end{array}\right]=\underbrace{\left[\begin{array}{ccc}
0 & \frac{\beta(1-\lambda)}{1-\beta \lambda} & \frac{\gamma \rho}{1-\beta \lambda} \\
0 & \frac{1-\lambda}{1-\beta \lambda} & \frac{\gamma \rho \lambda}{1-\beta \lambda} \\
0 & 0 & \rho
\end{array}\right]}_{\mathbf{A}}\left[\begin{array}{c}
\pi_{t-1} \\
\widehat{E}_{t-1} \pi_{t} \\
y_{t-1}
\end{array}\right]+\underbrace{\left[\begin{array}{cc}
\frac{\gamma}{1-\beta \lambda} & \frac{1}{1-\beta \lambda} \\
\frac{\gamma \lambda}{1-\beta \lambda} & \frac{\lambda}{1-\beta \lambda} \\
1 & 0
\end{array}\right]}_{\mathbf{B}}\left[\begin{array}{c}
u_{t} \\
\varepsilon_{t}
\end{array}\right],
$$

\footnotetext{
${ }^{16}$ For details of the derivation of (11), see Nerlove (1967, pp. 141-143). His results are expressed as a formula for $1-\lambda$.
} 
where $\lambda$ appears in numerous coefficients. The variance-covariance matrix $\mathbf{V}$ of the left-side variables in equation (12) can be computed using the formula:

$$
\operatorname{vec}(\mathbf{V})=[\mathbf{I}-\mathbf{A} \otimes \mathbf{A}]^{-1} \operatorname{vec}\left(\mathbf{B} \boldsymbol{\Omega} \mathbf{B}^{\prime}\right),
$$

where $\boldsymbol{\Omega}$ is the variance-covariance matrix of the fundamental shocks $u_{t}$ and $\varepsilon_{t}$. Since the matrix A contains only five non-zero elements, straightforward (but tedious) computations yield the following analytical expressions for the unconditional moments:

$$
\begin{aligned}
\operatorname{Var}\left(\widehat{E}_{t} \pi_{t+1}\right)= & {\left[\frac{1-\beta \lambda+\rho(1-\lambda)}{1-\beta \lambda-\rho(1-\lambda)}\right]\left\{\frac{\gamma^{2} \lambda^{2} \sigma_{u}^{2}}{\left[(1-\beta \lambda)^{2}-(1-\lambda)^{2}\right]\left(1-\rho^{2}\right)}\right\} } \\
& +\frac{\lambda_{\varepsilon}^{2}}{(1-\beta \lambda)^{2}-(1-\lambda)^{2}}, \\
\operatorname{Var}\left(\pi_{t}\right)= & {\left[1+\frac{2 \beta \rho \lambda(1-\lambda)}{1-\beta \lambda-\rho(1-\lambda)}\right]\left[\frac{\gamma^{2} \sigma_{u}^{2}}{(1-\beta \lambda)^{2}\left(1-\rho^{2}\right)}\right] } \\
& +\frac{\sigma_{\varepsilon}^{2}}{(1-\beta \lambda)^{2}+\left[\frac{\beta^{2}(1-\lambda)^{2}}{(1-\beta \lambda)^{2}}\right] \operatorname{Var}\left(\widehat{E}_{t} \pi_{t+1}\right),} \\
\operatorname{Cov}\left(\pi_{t}, \pi_{t-1}\right)= & \left\{\rho+\left[\frac{\beta \lambda(1-\lambda)}{(1-\beta \lambda)}\right]\left[\frac{\rho \beta \lambda(1-\lambda)+\left(1+\rho^{2}\right)(1-\beta \lambda)}{1-\beta \lambda-\rho(1-\lambda)}\right]\right\} \\
& \times\left[\frac{\gamma^{2} \sigma_{u}^{2}}{(1-\beta \lambda)^{2}\left(1-\rho^{2}\right)}\right]+\frac{\beta \lambda(1-\lambda) \sigma_{\varepsilon}^{2}}{(1-\beta \lambda)^{3}} \\
& +\left[\frac{\beta^{2}(1-\lambda)^{3}}{(1-\beta \lambda)^{3}}\right] \operatorname{Var}\left(\widehat{E}_{t} \pi_{t+1}\right), \\
\left.\widehat{E}_{t} \pi_{t+1}, y_{t}\right)= & \frac{\gamma \lambda \sigma_{u}^{2}}{[1-\beta \lambda-\rho(1-\lambda)]\left(1-\rho^{2}\right)},
\end{aligned}
$$

which are all nonlinear in the gain parameter $\lambda$. From equation (16), we see that inflation persistence is always positive, but the precise magnitude depends on the value of $\lambda$ and several other parameters in a rather complicated way. Equation (17) shows that the agent's inflation forecast is positively correlated with the driving variable $y_{t}$, similar to the case of rational expectations.

\subsubsection{Defining the Consistent Expectations Equilibrium}

This section defines the concept of a "consistent expectations equilibrium" along the lines of Hommes and Sorger (1998). By applying the results of Proposition 1, the value of the 
Kalman gain parameter $\lambda$ can be pinned down using the unconditional moments of $\Delta \pi_{t}$. By construction of the equilibrium, the agent's forecast rule will be parameterized such that the perceived law of motion (PLM) and the actual law of motion (ALM) exhibit the same firstorder autocorrelation for $\Delta \pi_{t} .{ }^{17}$ The following expression for $\Delta \pi_{t}$ can be derived from the actual law of motion:

$$
\begin{aligned}
\Delta \pi_{t}= & \underbrace{\left[\frac{\gamma}{1-\beta \lambda}\right]}_{a_{u}} u_{t}+\underbrace{\left[\frac{\gamma}{1-\beta \lambda}\right]\left[\frac{\beta \lambda(1-\lambda)}{1-\beta \lambda}+\rho-1\right]}_{b_{u}} u_{t-1} \\
& +\underbrace{\left[\frac{1}{1-\beta \lambda}\right]}_{a_{\varepsilon}} \varepsilon_{t}+\underbrace{\left[\frac{1}{1-\beta \lambda}\right]\left[\frac{\beta \lambda(1-\lambda)}{1-\beta \lambda}-1\right]}_{b_{\varepsilon}} \varepsilon_{t-1} \\
& +\underbrace{\left[\frac{-\beta \lambda(1-\lambda)(1-\beta)}{(1-\beta \lambda)^{2}}\right]}_{a_{\pi}} \widehat{E}_{t-2} \pi_{t-1}+\underbrace{\left[\frac{\gamma \rho}{1-\beta \lambda}\right]\left[\frac{\beta \lambda(1-\lambda)}{1-\beta \lambda}+\rho-1\right]}_{a_{y}} y_{t-2},
\end{aligned}
$$

where the constants $a_{i}$ and $b_{i}$ are used here to represent combinations of parameters. Equation (18) can be used to compute the following unconditional moments:

$$
\begin{aligned}
\operatorname{Var}\left(\Delta \pi_{t}\right)= & {\left[a_{u}^{2}+b_{u}^{2}+\frac{a_{y}^{2}}{\left(1-\rho^{2}\right)}\right] \sigma_{u}^{2}+\left(a_{\varepsilon}^{2}+b_{\varepsilon}^{2}\right) \sigma_{\varepsilon}^{2} } \\
& +a_{\pi}^{2} \operatorname{Var}\left(\widehat{E}_{t} \pi_{t+1}\right)+2 a_{\pi} a_{y} \operatorname{Cov}\left(\widehat{E}_{t} \pi_{t+1}, y_{t}\right), \\
\operatorname{Cov}\left(\Delta \pi_{t}, \Delta \pi_{t-1}\right)= & \left\{b_{u}\left[a_{u}+a_{y}+\frac{a_{\pi} \gamma \lambda}{1-\beta \lambda}\right]+\frac{\rho}{1-\rho^{2}}\left[a_{y}^{2}+\frac{a_{\pi} a_{y} \gamma \lambda}{1-\beta \lambda}\right]\right\} \sigma_{u}^{2} \\
& +b_{\varepsilon}\left[a_{\varepsilon}+\frac{a_{\pi} \lambda}{1-\beta \lambda}\right] \sigma_{\varepsilon}^{2}+\frac{a_{\pi}^{2}(1-\lambda)}{1-\beta \lambda} \operatorname{Var}\left(\widehat{E}_{t} \pi_{t+1}\right) \\
& +\left[\frac{a_{\pi}^{2} \gamma \rho \lambda}{1-\beta \lambda}+a_{\pi} a_{y}\left(\frac{1-\lambda}{1-\beta \lambda}+\rho\right)\right] \operatorname{Cov}\left(\widehat{E}_{t} \pi_{t+1}, y_{t}\right),
\end{aligned}
$$

where $\operatorname{Var}\left(\widehat{E}_{t} \pi_{t+1}\right)$ is given by equation (14) and $\operatorname{Cov}\left(\widehat{E}_{t} \pi_{t+1}, y_{t}\right)$ is given by equation (17). Dividing equation (20) by equation (19) yields an expression for $\operatorname{Corr}\left(\Delta \pi_{t}, \Delta \pi_{t-1}\right)$ which is nonlinear in the gain parameter $\lambda$. This nonlinear expression is employed in the following definition of equilibrium.

Definition 1. A consistent expectations equilibrium is defined as a perceived law of motion (10), an actual law of motion (12), and an associated Kalman gain parameter $\lambda$, such that $\lambda$

\footnotetext{
${ }^{17}$ In Hommes and Sorger (1998), the PLM is linear, whereas the ALM is nonlinear. Here, the PLM is nonstationary, whereas the ALM is stationary but highly persistent. In both cases, the PLM and the ALM exhibit an identical autocorrelation statistic.
} 
is the fixed point of the nonlinear map $\lambda=T(\lambda)$, where

$$
\begin{aligned}
T(\lambda) & =\frac{-\phi(\lambda)+\sqrt{\phi(\lambda)^{2}+4 \phi(\lambda)}}{2}, \\
\phi(\lambda) & =\frac{-1}{\operatorname{Corr}\left(\Delta \pi_{t}, \Delta \pi_{t-1}\right)}-2=\frac{-\operatorname{Var}\left(\Delta \pi_{t}\right)}{\operatorname{Cov}\left(\Delta \pi_{t}, \Delta \pi_{t-1}\right)}-2,
\end{aligned}
$$

with $\operatorname{Var}\left(\Delta \pi_{t}\right)$ and $\operatorname{Cov}\left(\Delta \pi_{t}, \Delta \pi_{t-1}\right)$ computed from the actual law of motion, as given by equations (19) and (20).

The equilibrium defined above is closely related to the concept of "optimal misspecified beliefs" described by Sargent (1999, Chapter 6). In Sargent's example, the gain parameter in the agent's adaptive forecast rule is chosen to minimize the one-step-ahead mean squared forecast error, given data generated by the actual law of motion. Here, the agent behaves similarly by choosing a Kalman gain that minimizes the mean squared forecast error for the perceived law of motion, given a signal-to-noise ratio that is inferred from data generated by the actual law of motion. In Sargent's example, the unit root in the agent's forecast rule compensates for an omitted constant. Here, the unit root in the agent's forecast rule compensates for the omitted driving variable $y_{t}$. In both cases, the agent's misspecified forecast rule alters the dynamics of the model in a way that tends to confirm the agent's belief in a unit root.

A more-complicated version of the model would allow the agent's subject forecast $\widehat{E}_{t} y_{t+1}$ to appear on the right side of equation (2), as in a micro-founded IS equation. If the agent's perceived law of motion for $y_{t}$ presumed the existence of a unit root, analogous to the form of (10), then the actual law of motion for $y_{t}$ would likely be very persistent but stationary, as assumed here. The Kalman gain parameters for the two subjective forecast rules $\widehat{E}_{t} y_{t+1}$ and $\widehat{E}_{t} \pi_{t+1}$ would then need to be determined simultaneously in equilibrium, possibly giving rise to multiple consistent expectations equilibria.

\section{Numerical Solution for the Equilibrium}

The complexity of the nonlinear map $\lambda=T(\lambda)$ necessitates a numerical solution for the equilibrium. To accomplish this, the model is calibrated using a set of parameter values that are either estimated directly or based on empirical estimates reported in the literature. I choose $\rho=0.90$ and $\sigma_{u}=0.01$ based on regressions using either the output gap (the deviation of log real GDP from log potential output) or labor's share of income (as a measure real marginal cost) over the period 1949.Q1 to 2004.Q4. ${ }^{18}$ Estimates of the NKPC parameters

\footnotetext{
${ }^{18}$ Data on real GDP are from http://research.stlouisfed.org/fred2/series/GDPC96. The potential output series used in this paper is the one constructed by the U.S. Congressional Budget Office. The series is available from http://research.stlouisfed.org/fred2/series/GDPPOT.mm. Labor's share of income is from http://www.bls.gov/data, using series ID PRS85006173.
} 
$\beta, \gamma$, and $\sigma_{\varepsilon}$ are sensitive to the choice of the driving variable, the specification for inflation expectations, the sample period, and the econometric method. ${ }^{19}$ Based on the various studies, I choose $\beta=0.98, \gamma=0.03$, and $\sigma_{\varepsilon}=0.01$ as baseline values. I also examine the sensitivity of the results to alternative parameter values.

Figure 2 plots $T(\lambda)$ over the range $0<\lambda \leq 1$ for two different values of $\gamma$. Other parameter configurations produced similarly-shaped $T(\lambda)$ maps. At the baseline calibration with $\gamma=$ 0.03 , the unique fixed point occurs at $\lambda^{*}=0.346$, which corresponds to $\operatorname{Corr}\left(\Delta \pi_{t}, \Delta \pi_{t-1}\right)=$ -0.458 . When $\gamma=0.08$, the unique fixed point occurs at $\lambda^{*}=0.695$, which corresponds to $\operatorname{Corr}\left(\Delta \pi_{t}, \Delta \pi_{t-1}\right)=-0.279$. Plausible values for the quarterly discount factor $\beta$ imply a near-unity coefficient on $\widehat{E}_{t} \pi_{t+1}$ in the NKPC equation (1). This feature of the model causes the agent's perception of a unit root in inflation to become close to self-fulfilling for most values of $\lambda$. As a result, the plot of $T(\lambda)$ lies very close to the 45-degree line for most values of $\lambda$. Similar results would likely obtain for any inflation equation that places a sizeable weight on expected inflation. The plot of $T(\lambda)$ suggests that inflation forecast accuracy is not likely to suffer much as long as $\lambda$ remains in the general vicinity of $\lambda^{*}$. This conjecture turns out to be true, as discussed later in section 6 .

[Figure 2 about here]

Table 1 shows the theoretical moments of $\Delta \pi_{t}$ predicted by the perceived law of motion (10) and the actual law of motion (12). By construction of the equilibrium, the standard deviation and the first-order autocorrelation are identical for the two laws of motion. The higher-order autocorrelations agree to the third decimal place, giving no obvious indication to the agent that the perceived law of motion is misspecified.

Table 1: Theoretical Moments of $\Delta \pi_{t}$

\begin{tabular}{ccc}
\hline \hline Statistic & Perceived Law of Motion & Actual Law of Motion \\
\hline $\operatorname{Std} . \operatorname{Dev} .\left(\Delta \pi_{t}\right)$ & 0.018 & 0.018 \\
$\operatorname{Corr}\left(\Delta \pi_{t}, \Delta \pi_{t-1}\right)$ & -0.458 & -0.458 \\
$\operatorname{Corr}\left(\Delta \pi_{t}, \Delta \pi_{t-2}\right)$ & 0 & -0.00017 \\
$\operatorname{Corr}\left(\Delta \pi_{t}, \Delta \pi_{t-3}\right)$ & 0 & -0.00019 \\
\hline Note: Parameter values are $\gamma=0.03, \beta=0.98, \rho=0.90, \sigma_{\varepsilon}=\sigma_{u}=0.01$.
\end{tabular}

Table 2 shows how equilibrium outcomes change with parameter values. Experiments with the model show that the value of $\lambda^{*}$ increases with the values of $\gamma, \beta, \rho$, and $\sigma_{u}^{2}$, but decreases with the value of $\sigma_{\varepsilon}^{2}$. Roughly speaking, parameter changes that increase the persistence of actual inflation have the effect of increasing the perceived signal-to-noise ratio and hence $\lambda^{*}$. Parameter changes that decrease the persistence of actual inflation have the effect of decreasing the perceived signal-to-noise ratio. The intuition for the effects of parameter changes is

\footnotetext{
${ }^{19}$ See, for example, Roberts (2005), Rudd and Whelan (2005a, 2007), Galí et al. (2005), and Fuhrer (2006).
} 
straightforward. From the agent's perspective, inflation is comprised of a persistent signal component $\bar{\pi}_{t}$ and a transitory noise component $v_{t}$. If a parameter shift causes observed inflation to become more persistent, then the agent's inferred value of the signal-to-noise ratio $\phi$ will increase.

Table 2 also reports the numerically-computed slope of the nonlinear map at the equilibrium point, i.e., $T^{\prime}\left(\lambda^{*}\right)$. The slope is only slightly below unity for most parameterizations of the model, again reflecting the fact that the map runs very close to the 45-degree line in the vicinity of $\lambda^{*}$.

At the baseline calibration (top left of Table 2), we have $\operatorname{Corr}\left(\pi_{t}, \pi_{t-1}\right)=0.90$ versus $\operatorname{Corr}\left(\pi_{t}^{\mathrm{re}}, \pi_{t-1}^{\mathrm{re}}\right)=0.23$. Under rational expectations, the autocorrelation coefficient shrinks rapidly as: (1) the fundamental shock ratio $\sigma_{\varepsilon}^{2} / \sigma_{u}^{2}$ increases, (2) the discount factor $\beta$ decreases, or (3) the driving variable persistence $\rho$ decreases. Under consistent expectations, the autocorrelation coefficient is much less sensitive to changes in these parameter values.

Table 2: Sensitivity Analysis

\begin{tabular}{cccccc}
\hline \hline & & & & \multicolumn{2}{c}{} \\
Variance & & \multicolumn{2}{c}{ Slope Parameter } & \multicolumn{2}{c}{ Persistence Parameters } \\
Ratio & Result & $\gamma=0.03$ & $\gamma=0.08$ & $\beta=0.96$ & $\rho=0.7$ \\
& $\phi^{*}$ & 0.18 & 1.58 & 0.08 & 0.10 \\
$\sigma_{\varepsilon}^{2} / \sigma_{u}^{2}=1$ & $\lambda^{*}$ & 0.35 & 0.70 & 0.25 & 0.27 \\
& $T^{\prime}\left(\lambda^{*}\right)$ & 0.98 & 0.90 & 0.98 & 0.99 \\
& $\operatorname{Corr}\left(\pi_{t}, \pi_{t-1}\right)$ & 0.90 & 0.93 & 0.76 & 0.86 \\
& $\operatorname{Corr}\left(\pi_{t}^{\mathrm{re}}, \pi_{t-1}^{\mathrm{re}}\right)$ & 0.23 & 0.64 & 0.18 & 0.01 \\
\hline & $\phi^{*}$ & 0.09 & 0.77 & 0.04 & 0.06 \\
$\sigma_{\varepsilon}^{2} / \sigma_{u}^{2}=2$ & $\lambda^{*}$ & 0.26 & 0.57 & 0.19 & 0.21 \\
& $T^{\prime}\left(\lambda^{*}\right)$ & 0.99 & 0.95 & 0.98 & 0.99 \\
& $\operatorname{Corr}\left(\pi_{t}, \pi_{t-1}\right)$ & 0.87 & 0.93 & 0.70 & 0.84 \\
& $\operatorname{Corr}\left(\pi_{t}^{\mathrm{re}}, \pi_{t-1}^{\mathrm{re}}\right)$ & 0.13 & 0.49 & 0.10 & 0.01 \\
\hline
\end{tabular}

Notes: Baseline values are $\gamma=0.03, \beta=0.98 \rho=0.90$, and $\sigma_{\varepsilon}=\sigma_{u}=0.01$.

Changes in $\sigma_{\varepsilon}^{2} / \sigma_{u}^{2}$ are accomplished by adjusting $\sigma_{\varepsilon}^{2}$ while maintaining $\sigma_{u}^{2}=(0.01)^{2}$.

Figure 3 shows how inflation dynamics are influenced by the Kalman gain. All parameters are set to their baseline values, but other parameter configurations produced similarly-shaped plots. For the parameter configurations examined in Table 2, we have $0.19 \leq \lambda^{*} \leq 0.70$. Panel 3a shows that inflation persistence is generally high, but drops off dramatically for $\lambda>0.9$ or $\lambda<0.1$. Panel $3 \mathrm{~b}$ shows that inflation volatility increases with $\lambda$ in a nonlinear fashion and always exceeds the corresponding value under rational expectations. The fact that inflation persistence and volatility can vary, depending on the value of $\lambda$, is an important feature that will be examined later in a "variable-gain" version of the model.

[Figure 3 about here]. 


\subsection{Real-Time Learning}

This section investigates the convergence properties of the consistent expectations equilibrium under real-time learning. Recall that the fixed point of the nonlinear map $\lambda=T(\lambda)$ is computed using the population autocorrelation $\operatorname{Corr}\left(\Delta \pi_{t}, \Delta \pi_{t-1}\right)$. This statistic presumes a fixed Kalman gain. However, in a real-time learning environment where the Kalman gain evolves over time, the agent will only have knowledge of the sample autocorrelation which, in turn, is influenced by the trajectory of the Kalman gain. The learning algorithm is described by a system of nonlinear stochastic difference equations summarized in Appendix A.

For each 200,000 period simulation, I set $\lambda_{t}=\lambda^{*}=0.346$ for the first 500 periods. Figure 4 plots the first 10,000 periods of each simulation, after which the results are not largely changed. The end-of-simulation values of the Kalman gain are clustered in the range where the theoretical map $T(\lambda)$ lies very close to the 45-degree line. Due to the shape of the map, a small amount of sampling variation in the autocorrelation coefficient can translate into sizable shifts in the Kalman gain, thereby affecting the speed of convergence and the end-ofsimulation value. For the eight learning simulations shown, the full-sample (200,000 period) autocorrelations are: $-0.484,-0.474,-0.467,-0.447,-0.441,-0.438,-0.414$, and -0.405 . The corresponding end-of-simulation gains are: $0.224,0.279,0.311,0.383,0.400,0.409,0.470$, and 0.490. Over the eight simulations, the average full-sample autocorrelation is -0.446 which is close to the theoretical model prediction of $\operatorname{Corr}\left(\Delta \pi_{t}, \Delta \pi_{t-1}\right)=-0.458$.

The sensitivity of the Kalman gain to the estimated autocorrelation coefficient is a feature of the nonlinear learning dynamics. This feature is incorporated into a "variable-gain" version of the model, to be discussed in Section 8.

[Figure 4 about here].

\section{Applying the Model's Methodology to U.S. Inflation Data}

Figure 5 provides a check on the reasonableness of the equilibrium values of $\phi^{*}$ and $\lambda^{*}$ implied by the model. Panel 4 a plots the 20 -year rolling autocorrelation coefficient for the change in U.S. GDP price inflation. The autocorrelation coefficient is negative throughout the sample. Panel $4 \mathrm{~b}$ plots the perceived signal-to-noise ratio computed directly from the autocorrelation coefficient using the formula in Proposition 1. The perceived signal-to-noise ratio fluctuates from a low of 0.1 to a high of 5.7. The upward spike that occurs in the early-1990s is due to the autocorrelation coefficient becoming less negative at that time. The perceived ratio drifts upward in the 1970s, remains high for about two decades, and then drifts downward from the mid-1990s onwards. Stock and Watson (2007) obtain similar results when estimating an unobserved-components model identical to (10) using data on U.S. GDP price inflation from 1953.Q1 to 2004.Q4. Assuming that the shock variances follow independent geometric random 
walks, Stock and Watson (2007) identify a statistically significant hump-shaped pattern for the variance of the permanent shock, but cannot reject the hypothesis of no change in the variance of the transitory shock. Piger and Rasche (2006) report a decline in the estimated variance of permanent shocks to U.S. inflation in the sample period after 1994.Q1. They interpret their results as "evidence that long-horizon inflation expectations have become better anchored" during this period. The foregoing results suggest that the signal-to-noise ratio identified from the data might be viewed as an inverse measure of the Fed's credibility for maintaining a constant inflation target.

[Figure 5 about here]

Roberts (2006) presents evidence that the slope parameter in reduced-form Phillips curve regressions has become smaller in recent decades. The consistent expectations model predicts that a decline in the Phillips curve slope parameter $\gamma$ will make actual inflation less persistent and therefore be accompanied by a decline in the perceived signal-to-noise ratio. The post1990 downward drift in the identified U.S. signal-to-noise ratio shown in panel $4 \mathrm{~b}$ could thus be partially attributable to a decline in the Phillips curve slope parameter.

Panel 4c plots the Kalman gain computed directly from the perceived signal-to-noise ratio using equation (11). The rolling sample period allows the Kalman gain to adjust to perceived shifts in the signal-to-noise ratio. The Kalman gain fluctuates from a low of 0.28 to a high of 0.87 , with the high also occurring in the early 1990s. Section 8 presents a "variable-gain" version of the model where $\lambda$ is pinned down using a rolling autocorrelation for $\Delta \pi_{t}$.

Figure 6 compares U.S. expected inflation to the corresponding model-based values. Expected inflation in U.S. data is measured by the 1-year ahead forecast for GDP price inflation from the Survey of Professional Forecasters. Comparisons with other surveys yielded similar results. The sample period for the survey starts in 1970.Q1. ${ }^{20}$ For the rational expectations (RE) version of the model, expected inflation is computed from equation (8) using the baseline parameter values. The driving variable is either the output gap or labor's share of income from U.S. data. ${ }^{21}$ For the consistent expectations (CE) version of the model, expected inflation is computed from equation (9) with $\lambda=0.346$, where $\pi_{t}$ is given by the realized value of U.S. GDP price inflation at time $t$. In other words, expected inflation for the CE model is an exponentially-weighted moving average of past realized U.S. GDP price inflation. The figure also plots expected inflation for a variable-gain version of the $\mathrm{CE}$ model, where the gain sequence is taken from the bottom panel of Figure $5 .^{22}$ The figure shows that the RE

\footnotetext{
${ }^{20}$ The survey is available from http://www.phil.frb.org/files/spf/cpie1.txt. It should be noted that modelbased values of expected inflation are annualized 1-quarter rates, whereas the survey data are 1-year ahead average inflation rates.

${ }^{21}$ Recall that equation (8) implies a steady-state inflation rate of zero. For comparison with the survey, the RE model-based values are shifted up by a constant to match the mean of U.S. inflation over the sample period.

${ }^{22}$ Both CE models employ the initial condition $\widehat{E}_{t-1} \pi_{t}=\pi_{t-1}$, where $\pi_{t-1}$ is U.S. GDP price inflation at 1968.Q4.
} 
model performs poorly in capturing observed movements in the survey-based measure of U.S. expected inflation, whereas both versions of the CE model perform well. The performance of the RE model could of course be improved by introducing a persistent exogenous process for the Fed's actual inflation target which would help capture the low frequency movements in the survey data.

[Figure 6 about here]

\section{Inflation Forecast Errors}

This section characterizes the unconditional moments of inflation forecast errors. When the actual law of motion for inflation is given by (12), the errors associated with the subjective forecast rule (9) exhibit near-zero autocorrelation for most values of $\lambda$. Furthermore, an agent who is concerned about minimizing forecast errors can become "locked-in" to the use of the subjective forecast. In particular, for most values of $\lambda$, the agent will perceive no accuracy gain from switching to a fundamentals-based inflation forecast. ${ }^{23}$

Suppose that the representative agent initially adopts the subjective forecast rule (9). The initial choice could be justified for reasons of computational or informational simplicity. The forecast error observed by the agent is given by

$$
\begin{aligned}
\operatorname{err}_{t+1} & =\pi_{t+1}-\widehat{E}_{t} \pi_{t+1} \\
& =\frac{\gamma}{(1-\beta \lambda)} u_{t+1}+\frac{1}{(1-\beta \lambda)} \varepsilon_{t+1}-\frac{(1-\beta)}{(1-\beta \lambda)} \widehat{E}_{t} \pi_{t+1}+\frac{\gamma \rho}{(1-\beta \lambda)} y_{t},
\end{aligned}
$$

where I have made use of the actual law of motion (12).

Now consider an agent who is contemplating a switch to a fundamentals-based inflation forecast. In deciding whether to switch forecasts, the agent keeps track of the forecast errors associated with each forecast method. Before any switch occurs, the actual law of motion for $\pi_{t}$ is still governed by (12). For simplicity, assume that enough time has gone by to allow the agent to have discovered the stochastic process for the fundamental driving variable $y_{t}$. Also assume that the agent has knowledge of the Phillips curve slope parameter $\gamma$ and the real-time value of the driving variable. With these assumptions, a fundamentals-based inflation forecast can be represented by the right-side of equation (8). The associated forecast error is given by

$$
\begin{aligned}
e r r_{t+1}^{\mathrm{f}} & =\pi_{t+1}-\left[\frac{\gamma \rho}{1-\rho \beta}\right] y_{t} \\
& =\frac{\gamma}{(1-\beta \lambda)} u_{t+1}+\frac{1}{(1-\beta \lambda)} \varepsilon_{t+1}+\frac{\beta(1-\lambda)}{(1-\beta \lambda)} \widehat{E}_{t} \pi_{t+1}-\frac{\gamma \rho \beta(\rho-\lambda)}{(1-\beta \lambda)(1-\rho \beta)} y_{t},(22)
\end{aligned}
$$

where the superscript " $\mathrm{f}$ " denotes the error associated with the fundamentals-based forecast.

\footnotetext{
${ }^{23}$ Lansing (2006) examines the concept of forecast lock-in using a standard Lucas-type asset pricing model.
} 


\subsection{Forecast Lock-in}

Given a sufficiently long time series of observations, the agent could compute the moments of the observed forecast errors under each of the above scenarios. Appendix B provides analytical expressions for the moments of the forecast errors. If the representative agent initially adopts the subjective forecast rule (9), then the associated fitness measure is given by $M S E \equiv$

$E\left[\left(\operatorname{err}_{t+1}\right)^{2}\right]$. Conditional on the same actual law of motion (12), the fitness measure for the fundamentals-based forecast is given by $M S E^{\mathrm{f}} \equiv E\left[\left(e r r_{t+1}^{\mathrm{f}}\right)^{2}\right]$. Forecast lock-in occurs if $M S E<M S E^{\mathrm{f}}$.

Figure 7 plots the moments of the inflation forecast errors for $0<\lambda \leq 1$. All parameters are set to the baseline values. For ease of comparison across panels, I plot the root mean squared error $R M S E$. Lower values imply a more accurate forecast. Vertical lines mark the value $\lambda^{*}$ that is consistent with the perceived law of motion (10).

[Figure 7 about here]

Panel 7a shows that the subjective forecast rule will become locked-in for $0<\lambda<0.98$. In this range, the combination of inflation persistence and volatility induced by the actual law of motion (12) cause the subjective forecast rule to be more accurate than the fundamentalsbased forecast. As $\lambda \rightarrow 1$, persistence declines and volatility rises (Figure 3), which has the effect of reducing the accuracy of the subjective forecast relative to the fundamentals-based forecast. Notice that the plot of $R M S E$ for the subjective forecast is relatively flat in the vicinity of $\lambda^{*}$. This validates the conjecture put forth earlier in the discussion of Figure 2; forecast accuracy does not change much as long as $\lambda$ remains in the general vicinity of $\lambda^{*}$.

The intuition for why lock-in occurs is straightforward. In computing the forecast fitness measures, the representative agent views the evolution of $\pi_{t}$ as being determined outside of his control. In equilibrium, of course, the chosen forecast rule does influence the evolution of $\pi_{t}$. When the agent initially adopts the subjective forecast rule (9), the resulting law of motion for $\pi_{t}$ is such that the fundamentals-based forecast is no longer the most accurate. Similar to the lock-in phenomena described by David (1985) and Arthur (1989), externalities that arise from an initial choice can lead to irreversibilities that may cause agents to stick with an inferior technology. Here, the subjective forecast rule (9) can be viewed as an inferior prediction technology because the mean squared forecast error could be lowered if the representative agent could be induced to switch to the fundamentals-based forecast.

\section{Other Models of Inflation Expectations}

Other models of inflation expectations have been proposed to address the shortcomings of the fully-rational NKPC. Two commonly-used setups are "hybrid expectations" and "sticky information." 
Hybrid expectations can be represented as

$$
\widehat{E}_{t}^{\text {he }} \pi_{t+1}=\omega E_{t} \pi_{t+1}+(1-\omega) \pi_{t-1},
$$

where expected inflation at time $t$ is a weighted-average of a rational forward-looking component $E_{t} \pi_{t+1}$ and a backward-looking component $\pi_{t-1}$. This setup can be motivated by the presence of some rule-of-thumb agents (Roberts 1997, Galí and Gertler 1999), alternative wage contracts (Buiter and Jewitt 1981, Fuhrer and Moore 1995), or the use of backward-looking price indexation by firms (Woodford 2003). The exogenous weighting parameter $\omega$ is typically set to a value around 0.5 .

Sticky information can be represented as

$$
\widehat{E}_{t}^{\mathrm{si}} \pi_{t+1}=\mu\left[E_{t} \pi_{t+1}+(1-\mu) E_{t-1} \pi_{t}+(1-\mu)^{2} E_{t-2} \pi_{t-1}+\ldots\right],
$$

where expected inflation at time $t$ is an exponentially-weighted moving average of current and past vintages of rational forecasts. The exogenous parameter $\mu$ can be interpreted as the fraction of agents in the economy who update to the current vintage forecast $E_{t} \pi_{t+1}$ each period. The sticky-information version of the NKPC was originally derived by Mankiw and Reis (2002). Using survey data on household and professional inflation forecasts, Carroll (2003) estimates $\mu=0.27$.

Table 3 compares theoretical moments for $\pi_{t}$ and $\Delta \pi_{t}$ across the various expectation models. ${ }^{24}$ In each case, $y_{t}$ is governed by equation (2). As noted earlier, the rational expectations (RE) model exhibits low inflation persistence, but it does predict a strong negative autocorrelation for the change in inflation - a robust feature of U.S. data. The hybrid expectations (HE) model is successful in generating more inflation persistence, as indicated by the result $\operatorname{Corr}\left(\pi_{t}, \pi_{t-1}\right)=0.87$. Counterfactually, however, the HE model predicts a weak negative autocorrelation for the change in inflation, with $\operatorname{Corr}\left(\Delta \pi_{t}, \Delta \pi_{t-1}\right)=-0.07$. This deficiency in the HE model has been pointed out by Cecchetti et al. (2007). The sticky information (SI) model exhibits an intermediate level of inflation persistence, while maintaining the strong negative autocorrelation for the change in inflation. The consistent expectations (CE) model generates high inflation persistence and a strong negative autocorrelation for the change in inflation. At the baseline parameterization, inflation volatility is highest for the $\mathrm{HE}$ and $\mathrm{CE}$ models.

\footnotetext{
${ }^{24}$ Details regarding the solutions of the HE and SI models are contained in Appendix C.
} 
Table 3: Comparison of Theoretical Inflation Moments

\begin{tabular}{|c|c|c|c|c|}
\hline \multirow[b]{2}{*}{ Statistic } & \multicolumn{4}{|c|}{ Expectation Model } \\
\hline & $\mathrm{RE}$ & $\begin{array}{c}\mathrm{HE} \\
\omega=0.5\end{array}$ & $\begin{array}{c}\text { SI } \\
\mu=0.27\end{array}$ & $\begin{array}{c}\mathrm{CE} \\
\lambda=0.346\end{array}$ \\
\hline $\operatorname{Corr}\left(\pi_{t}, \pi_{t-1}\right)$ & 0.23 & 0.87 & 0.46 & 0.90 \\
\hline $\operatorname{Corr}\left(\Delta \pi_{t}, \Delta \pi_{t-1}\right)$ & -0.49 & -0.07 & -0.50 & -0.46 \\
\hline Std. Dev. $\left(\pi_{t}\right)$ & 0.012 & 0.035 & 0.013 & 0.039 \\
\hline Std. Dev. $\left(\Delta \pi_{t}\right)$ & 0.014 & 0.018 & 0.014 & 0.018 \\
\hline
\end{tabular}

Numerous authors have demonstrated that U.S. inflation exhibits a gradual, hump-shaped response to unanticipated demand shocks. Although not plotted, the SI and the CE models exhibit very similar hump-shaped responses when subjected to a 1-standard deviation shock to $u_{t}$ in equation (2). A shift in $u_{t}$ can be interpreted as a surprise change in monetary policy that causes an unexpected shift in aggregate demand. ${ }^{25}$ The SI and CE models share a common trait. In both models, expected inflation (and hence inflation itself) is governed by a moving average algorithm which delivers a hump-shaped response.

A natural extension of the CE model (discussed in the next section) allows the Kalman gain $\lambda$ to vary over time, giving rise to time-varying persistence and volatility. The HE and SI models do not lend themselves to such an extension. Since $\omega$ and $\mu$ represent fractions of agents of a particular type in the economy, these parameters would be expected to remain fairly stable.

\section{Model Simulations}

Figure 8 plots simulated data for three different forms of inflation expectations. The left-side panels show the results for rational expectations. The middle panels show the results for consistent expectations, where the gain parameter is held constant at the theoretical equilibrium value $\lambda^{*}=0.346$ implied by Definition 1 . The right-side panels show the results for an alternative "variable-gain" version of the CE model that is described in Appendix A.

In the variable-gain model, the signal-to-noise ratio is inferred from the autocorrelation of $\Delta \pi_{t}$ over a 20-year (80-quarter) rolling sample period, analogous to the procedure used to construct Figure 5. The use of a rolling sample period allows for slowly-evolving perceptions of the signal-to-noise ratio, where perceptions are based on each generation's inflation experience. Alternatively, we may think of the representative agent as an econometrician who views 20year-old inflation data as being uninformative about the current value of $\phi$. Friedman (1979, p. 33) argues that most empirical time series analysis in economics is based on "some rough

\footnotetext{
${ }^{25}$ Mankiw and Reis (2002) demonstrate a hump-shaped impulse response to a demand shock in their version of the SI model.
} 
form of rolling sample period." 26

In the variable-gain model, the actual law of motion for inflation is nonlinear and thus capable of generating time-varying persistence and volatility. Recall that the model abstracts from any changes in the actual inflation trend; only the perceived trend is shifting. To achieve a meaningful comparison with U.S. data (which may be influenced by historical changes in the Fed's inflation target), I use a band pass filter to detrend both the model-generated data and the U.S. data.

[Figure 8 about here]

Comparing across panels $8 \mathrm{a}, 8 \mathrm{~b}$, and $8 \mathrm{c}$, we see that the same sequence of random shocks can lead to vastly different inflation dynamics, depending on the form of inflation expectations. The RE model's detrended inflation data exhibits very mild variation in persistence (panel 8d) and essentially no variation in volatility (panel $8 \mathrm{~g}$ ). Detrended inflation from the constant-gain CE model exhibits a fair amount of variation in persistence (panel 8e), but very little variation in volatility (panel 8h). Detrended inflation from the variable-gain CE model exhibits large variations in both persistence (panel 8f) and volatility (panel 8i).

Given that the variable-gain model is nonlinear, the rolling measures of persistence and volatility can exhibit intervals of rapid variation followed by intervals of relative stability. This behavior can be seen clearly in panels $8 \mathrm{f}$ and $8 \mathrm{i}$. Experiments with the model show that the agent's use of a shorter rolling sample period to infer the signal-to-noise ratio $\phi$ contributes to more rapid variation in persistence and volatility, but the rolling summary statistics can still exhibit irregular intervals of rapid variation interspersed with intervals of relative stability. Tables 4, 5, and 6 include results for the variable-gain model when the agent employs a shorter (40-quarter) rolling sample period to infer $\phi$.

In contrast to the RE model, both versions of the CE model produce low-frequency swings in the level of inflation, as measured by either the band pass filter trends (panels 8b and 8c) or the 20-year rolling sample means (panels $8 \mathrm{k}$ and 81 ). The low-frequency swings are not caused by changes in monetary policy. Instead, these movements derive solely from the nearrandom walk behavior of inflation under consistent expectations. To see this, note that the constant-gain CE version of the NKPC can be written as:

$$
\pi_{t}=\frac{\beta \lambda}{1-\beta \lambda}\left[(1-\lambda) \pi_{t-1}+(1-\lambda)^{2} \pi_{t-2}+\ldots\right]+\left[\frac{\gamma}{1-\beta \lambda}\right] y_{t}+\left[\frac{1}{1-\beta \lambda}\right] \varepsilon_{t},
$$

which implies that the sum of the weights on lagged inflation is $\beta(1-\lambda) /(1-\beta \lambda)=0.970$ when $\beta=0.98$ and $\lambda=0.346$. Given the highly persistent nature of $\pi_{t}$ observed in equilibrium, it would be very difficult for the agent to the reject the null hypothesis of a unit root in inflation, thus lending support for the perceived law of motion (10).

\footnotetext{
${ }^{26}$ Another approach would be to adopt one of the many variable-gain algorithms that have been developed in the vast literature on exponential smoothing. See, for example, Gardner (1985, p. 19).
} 
Figure 9 provides some additional justification for the variable-gain model. Panel 9a plots the signal-to-noise ratios inferred from the rolling autocorrelation of $\Delta \pi_{t}$ for both a constantgain and a variable-gain simulation. The inferred value of $\phi$ from the constant-gain simulation exhibits a fair amount of variation. Like Stock and Watson (2007), the agent may be inclined to view the shock variances $\sigma_{\eta}^{2}$ and $\sigma_{v}^{2}$ in equation (10) as stochastic variables. From the agent's perspective, the presence of stochastic volatility would justify a switch to a variable-gain forecasting algorithm. Once the switch occurs, the volatility of the perceived signal-to-noise ratio becomes magnified. The perception of stochastic volatility is thus self-confirming.

At times during the variable-gain simulation, the rolling sample autocorrelation of $\Delta \pi_{t}$ may yield the result that $\phi_{t}<0$, which is infeasible for a ratio of two variances. When this occurs, $\phi_{t}$ is set equal to $\phi_{t-1}$, i.e., the agent sticks with the previous estimate of the signalto-noise ratio if the most recent estimate is not economically reasonable. ${ }^{27}$ Similar results are obtained if the agent sets $\phi_{t}=0$ whenever the sample autocorrelation statistic yields the result $\phi_{t}<0$. Panel 9a shows that the sample autocorrelation statistic can imply $\phi_{t}<0$ for sustained intervals during the simulation. Low values of the signal-to-noise ratio imply a low value of the Kalman gain parameter which, in turn, serves to reduce inflation persistence and volatility as shown earlier in Figure 3. Consequently, a regime of low signal-to-noise ratios tends to be self-perpetuating.

[Figure 9 about here]

Panel 9b plots the time-path of the variable Kalman gain for one simulation. The average value of the gain over 200 simulations (each 2000 quarters in length) is 0.430. As noted earlier in reference to the real-time learning algorithm, the shape of the map $T(\lambda)$ implies that a small amount of sampling variation in the autocorrelation of $\Delta \pi_{t}$ can translate into sizable shifts in the Kalman gain. The gain rises sharply in response to upward spikes in the perceived signal-to-noise ratio. These recurring episodes might interpreted as "credibility crises" or "inflation scares," which cause the agent to heavily discount the central bank's past track record on inflation. Deflation scares are also possible. Lastly, panel 9c shows that when inflation is actually generated using the variable-gain forecast, the agent perceives no accuracy gain from switching to the fundamentals-based inflation forecast. The RMSE for each forecast is computed over a 20-year rolling sample period.

Table 4 provides a quantitative comparison of the forecast errors across the three forms of inflation expectations. The RE model delivers the most-accurate forecasts (as indicated by the lowest $R M S E$ value), whereas the variable-gain model delivers the least-accurate forecasts. However, as shown earlier, if the representative agent initially adopts the subjective forecast rule (9), then the agent is unlikely to perceive any accuracy gain from switching to

\footnotetext{
${ }^{27}$ Timmerman (1996, p. 538) adopts a similar projection facility when introducing learning in an asset pricing model.
} 
the fundamentals-based forecast. In the constant-gain model, the forecast errors are close to white noise. In the variable-gain model, the forecasts errors exhibit some weak negative autocorrelation, but it would take a large amount of data for the agent to reject the null hypothesis of white noise errors, especially given the sampling variation in the autocorrelation statistic. The explanation for the weak autocorrelation of forecast errors in the variable-gain model can be traced back to Figure 7, which shows that the autocorrelation statistic is very flat for most values of $\lambda$.

Table 4: Comparison of Inflation Forecast Errors

\begin{tabular}{ccccc}
\hline \hline & \multicolumn{4}{c}{ Model Simulations } \\
\cline { 2 - 5 } & \multicolumn{4}{c}{ CE-variable $\lambda$} \\
Statistic & 0.010 & CE-constant $\lambda$ & $T_{s}=80$ & $T_{s}=40$ \\
\hline$R M S E$ & 0.001 & 0.000 & -0.090 & -0.046 \\
$\operatorname{Corr}\left(e r r_{t}, e r r_{t-1}\right)$ & 0.000 & -0.001 & -0.037 & -0.059 \\
$\operatorname{Corr}\left(\operatorname{err}_{t}, \operatorname{err}_{t-2}\right)$ & -0.002 & -0.004 & -0.029 & -0.036 \\
$\operatorname{Corr}\left(\mathrm{err}_{t}, \mathrm{err}_{t-3}\right)$ & -002 &
\end{tabular}

Notes: Statistics above refer to raw data averaged over 200 simulations, where each simulation runs for 2000 quarters after dropping 200 quarters. $T_{s}=$ length of rolling sample period (in quarters) for computing the perceived signal-to-noise ratio $\phi$. Parameter values: $\gamma=0.03, \beta=0.98, \rho=0.90, \sigma_{\varepsilon}=\sigma_{u}=0.01$.

Table 5: Unconditional Moments, Raw and Detrended Data

\begin{tabular}{|c|c|c|c|c|c|c|}
\hline \multirow[b]{3}{*}{ Statistic } & \multicolumn{2}{|c|}{ U.S. Data } & \multicolumn{4}{|c|}{ Model Simulations } \\
\hline & \multirow{2}{*}{$\begin{array}{c}\text { CPI } \\
1871-2004\end{array}$} & \multirow{2}{*}{$\begin{array}{c}\text { GDP-PI } \\
1949-2004\end{array}$} & \multirow[b]{2}{*}{$\mathrm{RE}$} & \multirow[b]{2}{*}{ CE-constant $\lambda$} & \multicolumn{2}{|c|}{ CE-variable $\lambda$} \\
\hline & & & & & $T_{s}=80$ & $T_{s}=40$ \\
\hline \multirow{2}{*}{$\operatorname{Corr}\left(\pi_{t}, \pi_{t-1}\right)$} & 0.47 & 0.81 & 0.23 & 0.88 & 0.87 & 0.85 \\
\hline & 0.29 & 0.49 & 0.01 & 0.12 & 0.42 & 0.44 \\
\hline \multirow{2}{*}{$\operatorname{Corr}\left(\pi_{t}, \pi_{t-2}\right)$} & 0.22 & 0.74 & 0.20 & 0.87 & 0.82 & 0.78 \\
\hline & -0.02 & 0.32 & -0.02 & 0.06 & 0.23 & 0.23 \\
\hline \multirow{2}{*}{$\operatorname{Corr}\left(\pi_{t}, \pi_{t-3}\right)$} & 0.24 & 0.69 & 0.18 & 0.86 & 0.77 & 0.73 \\
\hline & 0.01 & 0.19 & -0.04 & 0.01 & 0.09 & 0.08 \\
\hline \multirow{2}{*}{ Std. Dev. $\left(\pi_{t}\right)$} & 0.084 & 0.026 & 0.012 & 0.038 & 0.066 & 0.088 \\
\hline & 0.073 & 0.016 & 0.010 & 0.014 & 0.032 & 0.045 \\
\hline $\operatorname{Corr}\left(\Delta \pi_{t}, \Delta \pi_{t-1}\right)$ & -0.27 & -0.34 & -0.48 & -0.46 & -0.31 & -0.28 \\
\hline
\end{tabular}

Notes: Statistics for $\pi_{t}$ are based on raw data (top number) and detrended data (bottom number). Statistics for $\Delta \pi_{t}$ are based on raw data. Model statistics are averaged over 200 simulations, where each simulation runs for 2000 quarters after dropping 200 quarters. $T_{s}=$ length of rolling sample (in quarters) for computing the perceived signal-to-noise ratio $\phi$. Parameter values: $\gamma=0.03$, $\beta=0.98, \rho=0.90, \sigma_{\varepsilon}=\sigma_{u}=0.01$.

Table 5 compares the moments of U.S. data with the corresponding moments from model simulations. Statistics are presented for both raw and detrended data. Again, I focus on the behavior of the detrended data. The persistence of detrended inflation is highest for the 
variable-gain model which yields a first-order autocorrelation of around 0.4 , thus providing the best match with detrended U.S. inflation data. The standard deviation of detrended inflation in the variable-gain model is 0.032 when $T_{s}=80$ and 0.045 when $T_{s}=40$. These are the largest values among the different models. The corresponding figure for long-run U.S. CPI inflation is 0.073, whereas the figure for post-World War II GDP price inflation is 0.016.

Table 6: Average Amplitude of Variation in 20-Year Rolling Summary Statistics

\begin{tabular}{|c|c|c|c|c|c|c|}
\hline \multirow[b]{3}{*}{ Statistic } & \multicolumn{2}{|c|}{ U.S. Data } & \multicolumn{4}{|c|}{ Model Simulations } \\
\hline & \multirow{2}{*}{$\begin{array}{c}\text { CPI } \\
1871-2004\end{array}$} & \multirow{2}{*}{$\begin{array}{c}\text { GDP-PI } \\
1949-2004\end{array}$} & \multirow[b]{2}{*}{$\mathrm{RE}$} & \multirow[b]{2}{*}{ CE-constant $\lambda$} & \multicolumn{2}{|c|}{ CE-variable $\lambda$} \\
\hline & & & & & $T_{s}=80$ & $T_{s}=40$ \\
\hline \multicolumn{7}{|l|}{$\operatorname{Corr}\left(\pi_{t}, \pi_{t-1}\right)$} \\
\hline 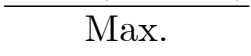 & 0.71 & 0.65 & 0.31 & 0.43 & 0.75 & 0.83 \\
\hline Min. & 0.07 & 0.15 & -0.30 & -0.21 & -0.26 & -0.27 \\
\hline \multicolumn{7}{|l|}{ Std. Dev. $\left(\pi_{t}\right)$} \\
\hline Max. & 0.125 & 0.020 & 0.013 & 0.017 & 0.096 & 0.141 \\
\hline Min. & 0.013 & 0.007 & 0.008 & 0.011 & 0.009 & 0.010 \\
\hline \multicolumn{7}{|l|}{ Mean $\left(\pi_{t}\right)$} \\
\hline Max. & 0.062 & 0.056 & 0.007 & 0.068 & 0.107 & 0.140 \\
\hline Min. & -0.031 & 0.021 & -0.007 & -0.067 & -0.102 & -0.142 \\
\hline
\end{tabular}

Notes: Statistics are the average maximum and average minimum values recorded over 200 simulations, where each simulation runs for 2000 quarters after dropping 200 quarters. Persistence and volatility statistics are based on detrended data. Mean statistics are based on raw data. $T_{s}=$ length of rolling sample period (in quarters) for computing the perceived signal-to-noise ratio $\phi$. Parameter values: $\beta=0.98$, $\gamma=0.03, \rho=0.90, \sigma_{\varepsilon}=\sigma_{u}=0.01$.

To provide a better sense of the invariant distributions generated by the different expectation models, Table 6 reports the average amplitude of variation of selected 20-year rolling summary statistics. The statistics for persistence and volatility are based on detrended data, whereas the statistics for the mean are based on raw data (since the mean of detrended data is zero by construction). The U.S. data exhibits large swings in the rolling summary statistics, as shown earlier in Figure 1. On average, the variable-gain model exhibits the largest swings in the rolling summary statistics. When the agent uses a shorter sample period $\left(T_{s}=40\right)$ to infer $\phi$ from past data, the amplitude of variation in the rolling summary statistics becomes somewhat larger.

An informal visual comparison between Figure 1 and Figure 8 shows that the variablegain model can generate time-varying persistence and volatility that is broadly similar to that observed in long-run U.S. data. The performance of the RE model on this front could of course be improved by introducing a heteroskedastic process for the driving variable $y_{t}$, or by introducing a persistent exogenous process for the central bank's actual inflation target. The results presented here suggest that complicated exogenous driving processes may not be 
needed to account for many features of U.S. inflation dynamics, if one is willing to entertain the idea of bounded rationality.

\section{Was the Great Inflation Caused by Bad Luck?}

An enormous literature has explored explanations for the "Great Inflation" of the 1970s and the subsequent "Volcker disinflation" of the early 1980s. Theories about the rise and fall of U.S. inflation fall roughly into one of three categories: (i) bad luck theories, (ii) policy mistake theories, and (iii) combination theories (where chance and policy discretion both play a role). One bad-luck theory is that U.S. inflation is governed by a unit-root process or something close to a unit root. This means that a sequence of white-noise shocks can generate large excursions in the inflation rate without any fundamental change in the underlying economy. According to this theory, there is nothing special about the 1970s and 1980s and similar events can happen again, given enough time. King and Watson (1994) present evidence that post-war U.S. inflation is indeed governed by a unit-root process.

The variable-gain CE model produces some episodes where the 20-year rolling measures of persistence, volatility, and mean of raw inflation all trace out hump-shaped patterns. ${ }^{28}$ The patterns are somewhat similar to those in post-World War II U.S. data. The simulation results suggest that white-noise fundamental shocks, propagated via the expectations feedback mechanism, could have played a role in producing the historical pattern of U.S. inflation. Along these lines, Blinder (1982) argues that oil and food price shocks, coupled with pent-up inflation from the release of the Nixon wage-price controls in 1974, can account for most of the rise in inflation during the 1970s. He also argues that the absence of these same factors can account for most of the fall in inflation during the early 1980s. More recently, Sims and Zha (2006) argue that the primary source of the rise and fall of U.S. inflation was a "changing array of major disturbances" that occurred during a relatively stable monetary policy regime.

Detailed historical studies by Hetzel (1998), Mayer (1999), and Nelson (2005) all emphasize the idea that monetary policymakers of the 1970s believed that much of the observed inflation was being driven by factors outside of the Fed's control. At the peak of the Great Inflation, Fed Chairman Volcker (1979, pp. 888-889) acknowledged the importance of inflation expectations as an independent driving force for realized inflation. He said: "Inflation feeds in part on itself, so part of the job of returning to a more stable and more productive economy must be to break the grip of inflationary expectations."

Notwithstanding the above discussion, changes in monetary policy do appear to have played a role in shaping the pattern of U.S. inflation - with the Volcker disinflation serving as the prime example. Research discussing this episode typically emphasizes the role of central bank

\footnotetext{
${ }^{28}$ When $T_{s}=80$, the average raw data correlation between the 20 -year rolling persistence measure and the 20 -year rolling volatility measure in the simulations is 0.64 . The average raw data correlation between the 20 -year rolling persistence measure and the 20-year rolling mean is 0.01 .
} 
credibility, noting that the rate at which credibility accumulates depends on the nature of inflation expectations. ${ }^{29}$ This idea connects well with the interpretation of the perceived signal-to-noise ratio as an inverse measure of central bank credibility.

A comprehensive study of the Great Inflation and the subsequent "Great Moderation" period of reduced macroeconomic volatility would require a fully-articulated model that includes both a micro-founded IS equation and a specification for shifts in monetary policy. The results presented here suggest that boundedly-rational inflation expectations may be a useful element of such a study.

\section{Concluding Remarks}

Evolving theories about inflation expectations, led by the contributions of Phelps (1967), Friedman (1968), Sargent (1971), and Lucas $(1972,1973)$ have played an important role in shaping the modern view of the Phillips curve. The current workhorse version for macroeconomics is the New Keynesian Phillips curve with rational expectations. The advantages of the NKPC are its tractability and its link to microfoundations that assume optimizing behavior on the part of agents and firms. The biggest disadvantage of the NKPC is its inability to account endogenously for some important quantitative features of U.S. inflation dynamics.

Rational expectations are sometimes called "model consistent expectations." A more precise term would be "actual-model consistent expectations," because the maintained assumption is that the agent knows the actual model. In contrast, the concept explored in this paper could be described as "perceived-model consistent expectations," because the agent's forecast rule is optimized for a perceived law of motion for inflation, given the observed moments of the inflation time series.

In the boundedly-rational NKPC examined here, expected inflation is an exponentiallyweighted moving average of past observed inflation rates. The observed autocorrelation of inflation changes is used to pin down the value of the Kalman gain parameter that governs the weights assigned to past rates of inflation in the agent's forecast rule. This result harkens back to the "accelerationist controversy" identified by Sargent (1971, p. 35) who argued persuasively that any forecast weighting scheme involving past rates of inflation should "be compatible with the observed evolution of the rate of inflation."

In the variable Kalman gain version of the model, endogenous shifts in the agent's perceived signal-to-noise ratio (which might be viewed as an inverse-measure of central bank credibility) give rise to changes in inflation persistence and volatility. These changes can take place in the absence of any underlying shifts in monetary policy. This feature of the model offers a possible explanation for the end-of-sample changes in U.S. inflation dynamics shown in Figure 1, which have occurred during a period of seemingly-unchanged monetary policy.

\footnotetext{
${ }^{29}$ For references to this large literature, see Huh and Lansing (2000) and Erceg and Levin (2003).
} 


\section{A Appendix: Real-Time Learning and Variable-Gain Model}

Real-time learning is discussed in Section 4 of the text. The learning algorithm is described by the following system of nonlinear equations

$$
\begin{aligned}
\pi_{t} & =\beta \widehat{E}_{t} \pi_{t+1}+\gamma y_{t}+\varepsilon_{t} \\
\widehat{E}_{t} \pi_{t+1} & =\widehat{E}_{t-1} \pi_{t}+\lambda_{t-1}\left(\pi_{t}-\widehat{E}_{t-1} \pi_{t}\right) \\
A v e_{t} & =\left[\frac{t}{t+1}\right] A v e_{t-1}+\left[\frac{1}{t+1}\right] \Delta \pi_{t} \\
n_{t} & =n_{t-1}+\left[\frac{t}{t+1}\right]\left(\Delta \pi_{t}-A v e_{t-1}\right)^{2} \\
m_{t} & =m_{t-1}+\left(\Delta \pi_{t}-A v e_{t-1}\right)\left[\Delta \pi_{t-1}-\frac{\Delta \pi_{t}}{(t+1)^{2}}-\frac{\left(t^{2}+3 t+1\right) A v e_{t-1}}{(t+1)^{2}}\right], \\
\phi_{t} & =-\frac{n_{t}}{m_{t}}-2 \\
\lambda_{t} & =\frac{\lambda_{t-1}+\phi_{t}}{1+\lambda_{t-1}+\phi_{t}}
\end{aligned}
$$

where $y_{t}$ is governed by equation (2). Equations (A.1) and (A.2) define the actual law of motion for inflation when the Kalman gain is evolving over time. Equations (A.3) through (A.5) are used to recursively estimate the autocorrelation of inflation changes using all past data. ${ }^{30}$ Equation (A.6) is the full-sample estimate of the signal-to-noise ratio. Equation (A.7) is the out-of-steady state version of the Kalman gain formula (11). ${ }^{31}$

To obtain the "variable-gain" version of the model that is discussed in Section 8 of the text, equations (A.3) through (A.5) are modified to compute the autocorrelation of inflation changes over a 20-year rolling sample period rather than over the full sample period. Both the real-time learning algorithm and the variable-gain model employ a "projection facility," which sets $\phi_{t}=\phi_{t-1}$ whenever the sample autocorrelation of $\Delta \pi_{t}$ yields the result that $\phi_{t}<0$.

\section{B Appendix: Moments of Inflation Forecast Errors}

This appendix provides analytical expressions for the moments used in plotting Figure 7 . Consider the case when the representative agent initially adopts the subjective forecast rule (9). In equilibrium, the actual law of motion is given by equation (12). Both the subjective forecast and the fundamentals-based forecast are unbiased, i.e., $E\left(e r r_{t+1}\right)=E\left(e r r_{t+1}^{f}\right)=0$.

Starting from (21), the fitness measure for the subject forecast is given by

$$
\begin{aligned}
M S E= & \frac{\gamma^{2} \sigma_{u}^{2}}{(1-\beta \lambda)^{2}\left(1-\rho^{2}\right)}+\frac{\sigma_{\varepsilon}^{2}}{(1-\beta \lambda)^{2}}+\frac{(1-\beta)^{2}}{(1-\beta \lambda)^{2}} \operatorname{Var}\left(\widehat{E}_{t} \pi_{t+1}\right) \\
& -\frac{2(1-\beta) \gamma \rho}{(1-\beta \lambda)^{2}} \operatorname{Cov}\left(\widehat{E}_{t} \pi_{t+1}, y_{t}\right)
\end{aligned}
$$

\footnotetext{
${ }^{30}$ These formulas are adapted from Hommes and Sorger (1998, pp. 320-321).

${ }^{31}$ For the derivation of equation (A.7), see McCulloch (2005). Use of the steady-state Kalman gain formula (11) with $\phi=\phi_{t}$ produced very similar results.
} 
where $\operatorname{Var}\left(\widehat{E}_{t} \pi_{t+1}\right)$ and $\operatorname{Cov}\left(\widehat{E}_{t} \pi_{t+1}, y_{t}\right)$ are given by (14) and (17).

Again starting from (21), it can be shown that the covariance of sequential forecast errors is given by

$$
\begin{aligned}
\operatorname{Cov}\left(\operatorname{err}_{t+1}, \text { err }_{t}\right)= & \frac{[\rho-\lambda+\beta \lambda(1-\rho)] \gamma^{2} \sigma_{u}^{2}}{(1-\beta \lambda)^{3}\left(1-\rho^{2}\right)}-\frac{(1-\beta) \lambda \sigma_{\varepsilon}^{2}}{(1-\beta \lambda)^{3}}+\frac{(1-\beta)^{2}(1-\lambda)}{(1-\beta \lambda)^{3}} \operatorname{Var}\left(\widehat{E}_{t} \pi_{t+1}\right) \\
& -\frac{(1-\beta) \gamma \rho[1+\rho+\beta \lambda(1-\rho)-2 \lambda]}{(1-\beta \lambda)^{3}} \operatorname{Cov}\left(\widehat{E}_{t} \pi_{t+1}, y_{t}\right) .
\end{aligned}
$$

Dividing the above equation by $M S E=\operatorname{Var}\left(e r r_{t+1}\right)$ from (B.1) yields a complicated expression for $\operatorname{Corr}\left(e r r_{t+1}, e r r_{t}\right)$. However, the following simplified version can be obtained by letting $\beta \rightarrow 1$

$$
\operatorname{Corr}\left(\operatorname{err}_{t+1}, e r r_{t}\right)_{\beta \rightarrow 1}=\frac{\gamma^{2} \rho}{\gamma^{2}+\left(1-\rho^{2}\right)\left(\sigma_{\varepsilon}^{2} / \sigma_{u}^{2}\right)},
$$

which bears a striking resemblance to the autocorrelation of inflation under rational expectations, as given by (6) A comparison of (6) and (B.3) reveals that parameter configurations which give rise to low autocorrelation of inflation under rational expectations will imply an even lower autocorrelation of forecast errors under the subjective forecast rule (9).

Next, we start from (22). The fitness measure for the fundamentals-based forecast is given by

$$
\begin{aligned}
M S E^{\mathrm{f}}= & \frac{\gamma^{2} \sigma_{u}^{2}}{(1-\beta \lambda)^{2}}\left[1+\frac{\rho^{2} \beta^{2}(\rho-\lambda)^{2}}{(1-\rho \beta)^{2}\left(1-\rho^{2}\right)}\right]+\frac{\sigma_{\varepsilon}^{2}}{(1-\beta \lambda)^{2}}+\frac{\beta^{2}(1-\lambda)^{2}}{(1-\beta \lambda)^{2}} \operatorname{Var}\left(\widehat{E}_{t} \pi_{t+1}\right) \\
& -\frac{2 \gamma \rho \beta^{2}(\rho-\lambda)(1-\lambda)}{(1-\beta \lambda)^{2}(1-\rho \beta)} \operatorname{Cov}\left(\widehat{E}_{t} \pi_{t+1}, y_{t}\right)
\end{aligned}
$$

where $\operatorname{Var}\left(\widehat{E}_{t} \pi_{t+1}\right)$ and $\operatorname{Cov}\left(\widehat{E}_{t} \pi_{t+1}, y_{t}\right)$ continue to be given by (14) and (17).

Proceeding as before, the covariance of sequential forecast errors is given by

$$
\begin{aligned}
\operatorname{Cov}\left(\operatorname{err}_{t+1}^{\mathrm{f}}, e r r_{t}^{\mathrm{f}}\right)= & \frac{\beta \gamma^{2} \sigma_{u}^{2}}{(1-\beta \lambda)^{3}}\left[1-\frac{\rho^{2} \beta(\rho-\lambda)}{(1-\rho \beta)\left(1-\rho^{2}\right)}\right]\left[\lambda(1-\lambda)-\frac{\rho(\rho-\lambda)(1-\beta \lambda)}{(1-\rho \beta)}\right] \\
& +\frac{\gamma \rho \beta^{2}(1-\lambda)}{(1-\beta \lambda)^{3}}\left[\lambda(1-\lambda)-\frac{(\rho-\lambda)[\rho(1-\beta \lambda)+1-\lambda]}{(1-\rho \beta)}\right] \operatorname{Cov}\left(\widehat{E}_{t} \pi_{t+1}, y_{t}\right) \\
& +\frac{\beta \lambda(1-\lambda) \sigma_{\varepsilon}^{2}}{(1-\beta \lambda)^{3}}+\frac{\beta^{2}(1-\lambda)^{3}}{(1-\beta \lambda)^{3}} \operatorname{Var}\left(\widehat{E}_{t} \pi_{t+1}\right),
\end{aligned}
$$

which can be divided by equation (B.4) to obtain an expression for $\operatorname{Corr}\left(e r r_{t+1}^{\mathrm{f}}, e r r_{t}^{\mathrm{f}}\right)$.

\section{Appendix: Other Models of Inflation Expectations}

This appendix outlines the model solutions discussed in Section 7 of the text. 


\section{C.1 Hybrid Expectations}

Substituting equation (23) into the NKPC (1) and then solving for the equilibrium law of motion using the method of undetermined coefficients yields

$$
\pi_{t}=d_{\pi} \pi_{t-1}+\left[\frac{\gamma}{1-\left(\rho+d_{\pi}\right) \beta \omega}\right] y_{t}+\left[\frac{1}{1-\left(\rho+d_{\pi}\right) \beta \omega}\right] \varepsilon_{t},
$$

where $d_{\pi}$ is the smaller root of the quadratic equation $\beta \omega\left(d_{\pi}\right)^{2}-d_{\pi}+\beta(1-\omega)=0$. At the baseline parameter values with $\omega=0.5$, we have $d_{\pi}=0.82$. From (C.1), the rational forward-looking component in (23) is given by

$$
E_{t} \pi_{t+1}=d_{\pi} \pi_{t}+\left[\frac{\rho \gamma}{1-\left(\rho+d_{\pi}\right) \beta \omega}\right] y_{t}
$$

which reduces to the RE model forecast (8) when $\omega=1$ such that $d_{\pi}=0$.

\section{C.2 Sticky Information}

Equation (24) can be written in recursive form as $\widehat{E}_{t}^{\mathrm{si}} \pi_{t+1}=\mu E_{t} \pi_{t+1}+(1-\mu) \widehat{E}_{t-1}^{\mathrm{si}} \pi_{t}$. Substituting the recursive form into the NKPC (1) and then solving for the equilibrium law of motion using the method of undetermined coefficients yields the following system of equations

$$
\begin{aligned}
\pi_{t} & =d_{\pi} \widehat{E}_{t-1}^{\mathrm{si}} \pi_{t}+\left[\frac{\gamma\left(1-\mu d_{\pi}\right)}{1-\left(\rho \beta+d_{\pi}\right) \mu}\right] y_{t}+\varepsilon_{t}, \\
\widehat{E}_{t}^{\mathrm{si}} \pi_{t+1} & =\left[\frac{1-\mu}{1-\mu d_{\pi}}\right] \widehat{E}_{t-1}^{\mathrm{si}} \pi_{t}+\left[\frac{\rho \gamma \mu}{1-\left(\rho \beta+d_{\pi}\right) \mu}\right] y_{t},
\end{aligned}
$$

where $d_{\pi}$ is the smaller root of the quadratic equation $\mu\left(d_{\pi}\right)^{2}-d_{\pi}+\beta(1-\mu)=0$. At the baseline parameter values with $\mu=0.27$, we have $d_{\pi}=0.97$. From (C.3), the current vintage rational forecast is given by

$$
E_{t} \pi_{t+1}=d_{\pi} \widehat{E}_{t}^{\mathrm{si}} \pi_{t+1}+\left[\frac{\rho \gamma\left(1-\mu d_{\pi}\right)}{1-\left(\rho \beta+d_{\pi}\right) \mu}\right] y_{t}
$$

which reduces to the RE model forecast (8) when $\mu=1$ such that $d_{\pi}=0$. 


\section{References}

Ang, A., G. Bekaert, and M. Wei (2007). "Do Macro variables, asset markets, or surveys forecast inflation better?" Journal of Monetary Economics, 54, 1163-1212.

Arthur, W.B. (1989). "Competing technologies, increasing returns, and lock-in by historical small events," Economic Journal, 99, 116-131.

Ascari, G. (2004). "Staggered prices and trend inflation: some nuisances" Review of Economic Dynamics, 7, 642-667.

Atkeson, A. and L.E. Ohanian (2001). "Are Phillips curves useful for forecasting inflation?" FRB Minneapolis Quarterly Review, Winter, 2-11.

Ball, L. (2000). "Near-rationality and inflation in two monetary regimes," National Bureau of Economic Research, Working Paper 7988.

Barsky, R.B. (1987). "The Fisher hypothesis and the forecastability and persistence of inflation," Journal of Monetary Economics, 19, 3-24.

Blinder, A.S. (1982). "The anatomy of double-digit inflation in the 1970s", in R. Hall, ed., Inflation: Causes and Effects. Chicago: University of Chicago Press, pp. 261-282.

Boivin, J. and M. Giannoni (2006). "Has monetary policy become more effective?" Review of Economics and Statistics, 88, 445-462.

Branch, W.A. (2004). "Theory of rationally heterogeneous expectations: evidence from survey data on inflation expectations," Economic Journal, 114, 592-621.

Buiter, W.H., and I. Jewitt (1981). "Staggered wage setting with real wage relativities: Variations on a theme of Taylor," The Manchester School, 49, 211-228.

Calvo, G.A. (1983). "Staggered prices in a utility maximizing framework," Journal of Monetary Economics, 12, 383-398.

Carroll, C. (2003). "Macroeconomic expectations of households and professional forecasters," Quarterly Journal of Economics, 118, 269-298.

Cecchetti, S.G., P. Hooper, B.C. Kasman, K.L. Schoenholtz, and M. Watson (2007). "Understanding the evolving inflation process," Paper presented at the U.S. Monetary Policy Forum 2007.

Christiano, L.J. and T.J. Fitzgerald (2003). "The band pass filter," International Economic Review, 44, 435-465.

Cogley, T. and T.J. Sargent (2002). "Evolving post-World War II U.S. inflation dynamics," in B. Bernanke and K. Rogoff, eds., NBER Macroeconomics Annual 2001. Cambridge MA: MIT Press, pp. 331-373.

Cogley, T. and T.J. Sargent (2005). "Drifts and volatilities: monetary policies and outcomes in the post WWII U.S.," Review of Economic Dynamics, 8, 262-302.

Cogley, T. and A.M. Sbordone (2008). "Trend inflation, indexation, and inflation persistence in the new Keynesian Phillips curve," American Economic Review, forthcoming.

David, P. (1985). "Clio and the economics of QWERTY." American Economic Review, Papers and Proceedings, 75, 332-337.

Erceg, C.J. and A.T. Levin (2003). "Imperfect credibility and inflation persistence," Journal of Monetary Economics, 50,915-944.

Estrella, A. and J.C. Fuhrer (2002). "Dynamic inconsistencies: Counterfactual implications of a class of rational-expectations models," American Economic Review, 92, 1013-1028.

Evans, G.W. and S. Honkapohja (1993). "Adaptive forecasts, hysteresis, and endogenous fluctuations," Federal Reserve Bank of San Francisco, Economic Review, No. 1, pp. 3-13.

Evans, G.W. and S. Honkapohja (2001). Learning and expectations in economics. Princeton: Princeton University Press. 
Evans, G.W. and G. Ramey (2006). "Adaptive expectations, underparameterization, and the Lucas critique," Journal of Monetary Economics, 53, 249-264.

Fuhrer J.C. (1997). "The (un)importance of forward-looking behavior in price specifications," Journal of Money Credit and Banking, 29, 338-350.

Fuhrer J.C. (2006). "Intrinsic and inherited inflation persistence," International Journal of Central Banking, 2, 49-86.

Fuhrer J.C. and G. Moore (1995). "Inflation persistence," Quarterly Journal of Economics, 110, 127-160.

Friedman, M. (1968). "The role of monetary policy," American Economic Review, 58, 1-17.

Friedman, B.M. (1979). "Optimal expectations and the extreme information assumptions of rational expectations models," Journal of Monetary Economics, 5, 23-41.

Galí, J. and M. Gertler (1999). "Inflation dynamics: A structural econometric analysis," Journal of Monetary Economics, 44, 195-222.

Galí, J., M. Gertler, and J. D. López-Salido (2005). "Robustness of the estimates of the hybrid New Keynesian Phillips curve," Journal of Monetary Economics, 52, 1107-1118.

Gardner, E.S., Jr. (1985). "Exponential smoothing: The state of the art," Journal of Forecasting, 4, 1-28.

Harvey, A.C. (1993). Time Series Models. MIT Press.

Hetzel, R.L. (1998). "Arthur Burns and inflation," Federal Reserve Bank of Richmond, Economic Quarterly, 84, 21-44.

Hommes, C. and G. Sorger (1998). "Consistent expectations equilibria," Macroeconomic Dynamics, 2, 287-321.

Huh, C.G. and K.J. Lansing (2000). "Expectations, credibility, and disinflation in a small macroeconomic model," Journal of Economics and Business, 51, 51-86.

Ireland. P.N. (2007). "Changes in the Federal Reserve's inflation target: Causes and consequences," Journal of Money, Credit, and Banking, 39, 1851-1882.

King, R.G. and M.W. Watson (1994). "The post-war U.S. Phillips curve: A revisionist econometric history," Carnegie-Rochester Conference Series on Public Policy, 41, 157-219.

Klein, B. (1978). "The measurement on long- and short-term price uncertainty: A moving regression time series analysis," Economic Inquiry, 16, 438-452.

Kozicki, S. and P.A. Tinsley (2002). "Alternative sources of the lag dynamics of inflation," Price Adjustment and Monetary Policy Conference Proceedings, Bank of Canada.

Kozicki, S. and P.A. Tinsley (2005). "Permanent and transitory policy shocks in an empirical macro model with asymmetric information," Journal of Economic Dynamics and Control, 29, 1985-2015.

Lansing, K.J. (2006). "Lock-in of extrapolative expectations in an asset pricing model," Macroeconomic Dynamics, 10, 317-348.

Levin, A.T. and J.M. Piger. (2004). "Is inflation persistence intrinsic in industrial economies?" European Central Bank, Working Paper No. 334.

Lucas, R.E., Jr. (1972). "Expectations and the neutrality of money," Journal of Economic Theory, 4, 103-124.

Lucas, R.E., Jr. (1973). "Some international evidence on output-inflation trade-offs," American Economic Review, 63, 326-334.

Mankiw, N.G. (2001). "The inexorable and mysterious tradeoff between inflation and unemployment," Economic Journal, 111, C45-C61.

Mankiw, N.G. and R. Reis. (2002). "Sticky information versus sticky prices: A proposal to replace the New Keynesian Phillips curve," Quarterly Journal of Economics, 117, 1295-1328. 
Mankiw, N.G., R. Reis, and J. Wolfers (2004). "Disagreement about inflation expectations," in M. Gertler and K. Rogoff, eds., NBER Macroeconomics Annual 2003. Cambridge MA: MIT Press, pp. 209-248.

Marques, C.R. (2004). "Inflation persistence: Facts or artefacts?" European Central Bank, Working Paper No. 371.

Mayer, T. (1999). Monetary Policy and the Great Inflation in the United States. Cheltanham, UK: Edward Elgar.

McCulloch, J.H. (2005). "The Kalman foundations of adaptive least squares, with application to U.S. inflation," Ohio State University, Working Paper.

Milani, F. (2005). "Adaptive learning and inflation persistence," Princeton University, Working Paper.

Muth, J.F. (1960). "Optimal properties of exponentially weighted forecasts," Journal of the American Statistical Association, 55, 299-306.

Nelson, E. (2005). "The great inflation of the seventies: What really happened?" Advances in Macroeconomics, 5(1).

Nerlove, M. (1967). "Distributed lags and unobserved components in economic time series," in W. Fellner, ed., Ten Economic Studies in the Tradition of Irving Fischer. New York: John Wiley \& Sons, pp. 127-169.

Orphanides, A. and S. Van Norden (2005). "The reliability of inflation forecasts based on output gap estimates in real time," Journal of Money Credit and Banking, 37, 583-601.

Orphanides, A. and J.C. Williams (2005). "Imperfect knowledge, inflation expectations, and monetary policy," in B. Bernanke and M. Woodford, eds., The Inflation Targeting Debate. Chicago: University of Chicago Press, pp. 201-234.

Phelps, E.S. (1967). "Phillips curves, expectations of inflation and optimal unemployment over time," Economica, 34, 254-281.

Piger, J.M. and R.H. Rasche (2006). "Inflation: Do expectations trump the gap?" Federal Reserve Bank of St. Louis, Working Paper 2006-013A.

Pivetta, F. and R. Reis (2007). "The persistence of inflation in the United States," Journal of Economic Dynamics and Control, 31, 1326-1358.

Preston, B. (2005). "Learning about monetary policy rules when long-horizon expectations matter," International Journal of Central Banking, 1, 81-126.

Roberts, J. (1997). "Is inflation sticky?" Journal of Monetary Economics, 39, 173-196.

Roberts, J. (2005). "How well does the New Keynesian sticky-price model fit the data?" Contributions to Macroeconomics, 5(1).

Roberts, J. (2006). "Monetary policy and inflation dynamics," International Journal of Central Banking, 2, 193-230.

Rudd, J.B. and K. Whelan (2005a). "New tests of the New-Keynesian Phillips curve," Journal of Monetary Economics, 53, 1167-1181.

Rudd, J.B. and K. Whelan (2005b). "Does labor's share drive inflation?" Journal of Money, Credit, and Banking, 37, 297-312.

Rudd, J.B. and K. Whelan (2007). "Modeling inflation dynamics: A critical review of recent research," Journal of Money, Credit, and Banking, 39, 155-170.

Sahuc, J.-G. (2006). "Partial indexation, trend inflation, and the hybrid Phillips curve," Economics Letters, 90, 42-50.

Sargent, T. (1971). "A note on the 'accelerationist' controversy," Journal of Money, Credit, and Banking, 3, 721-725.

Sargent, T.J. (1999). The Conquest of American Inflation. Princeton: Princeton University Press. 
Sims, C.A. and T. Zha (2006). "Were there regime switches in U.S. monetary policy?" American Economic Review, 96, 54-81.

Stock, J.H. and M.W. Watson (2007). "Why has inflation become harder to forecast?" Journal of Money, Credit, and Banking, 39, 3-34.

Timmerman, A. (1996) "Excess volatility and predictability of stock prices in autoregressive dividend models with learning," Review of Economic Studies 63, 523-557.

Volcker, P.A. (1979). "Statement" before the Joint Economic Committee, Federal Reserve Bulletin, 65 (November), 888-890.

Warren, G.F. and F.A. Pearson (1935). Gold and Prices. New York: John Wiley \& Sons..

Williams, J.C. (2006). "Inflation Persistence in an Era of Well-Anchored Inflation Expectations," FRBSF Economic Letter 2006-27, October 13.

Woodford, M. (2003). Interest and prices: Foundations of a theory of monetary policy. Princeton: Princeton University Press. 
1a: CPI Inflation 1871.Q2 to 2004.Q4

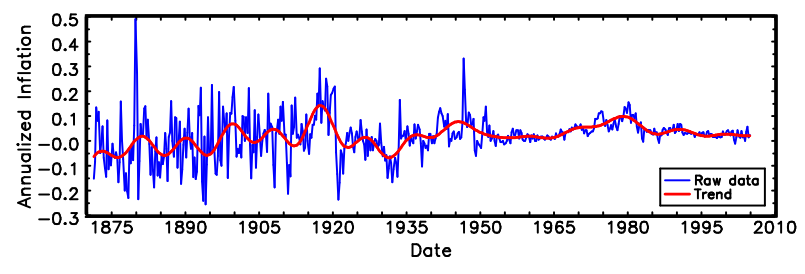

1c: Persistence of CPI Inflation

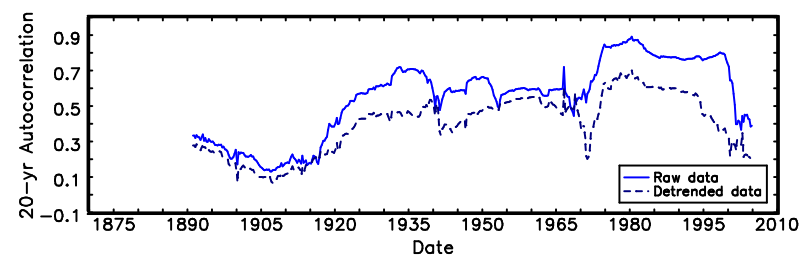

1e: Volatility of CPI Inflation

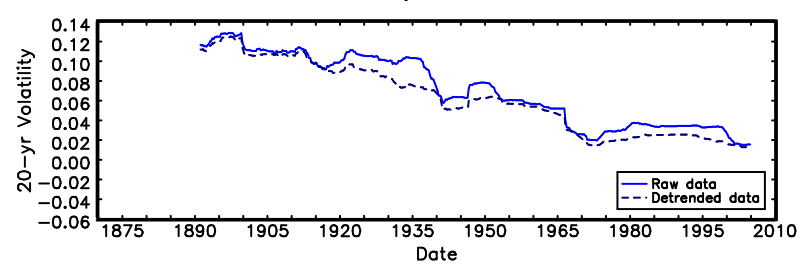

$1 \mathrm{~g}:$ Mean of CPI Inflation

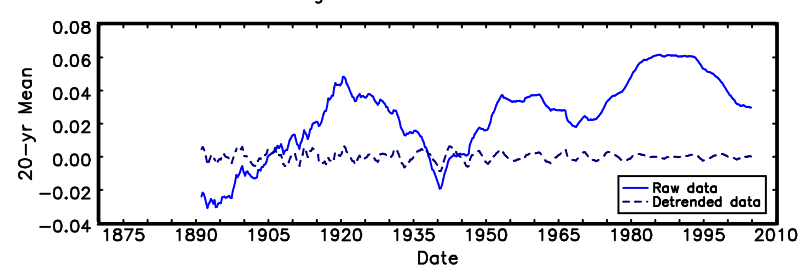

1b: GDP Price Inflation 1949.Q1 to 2004.Q4

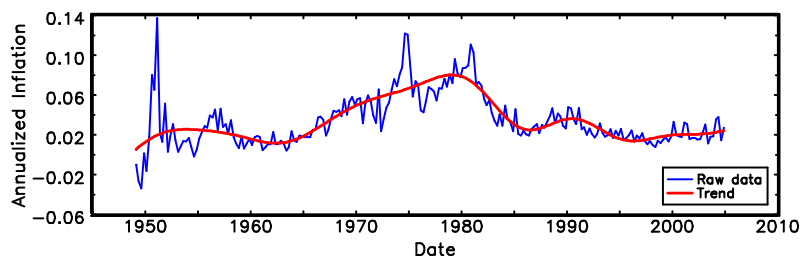

1d: Persistence of GDP Price Inflation

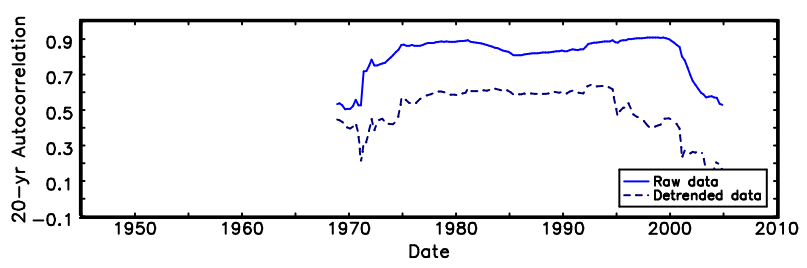

1f: Volatility of GDP Price Inflation

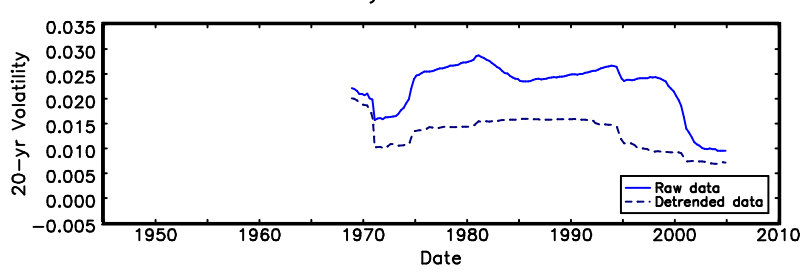

1h: Mean of GDP Price Inflation

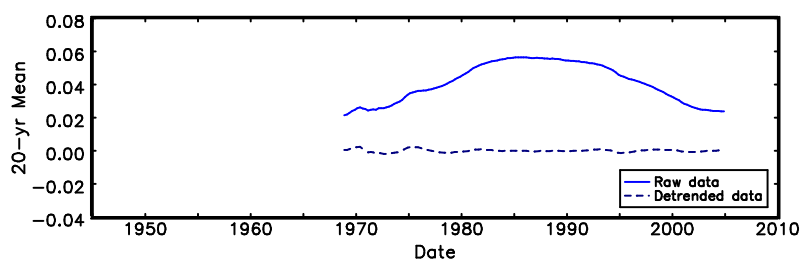

Figure 1: Long-run U.S. inflation data and 20-year rolling summary statistics. 


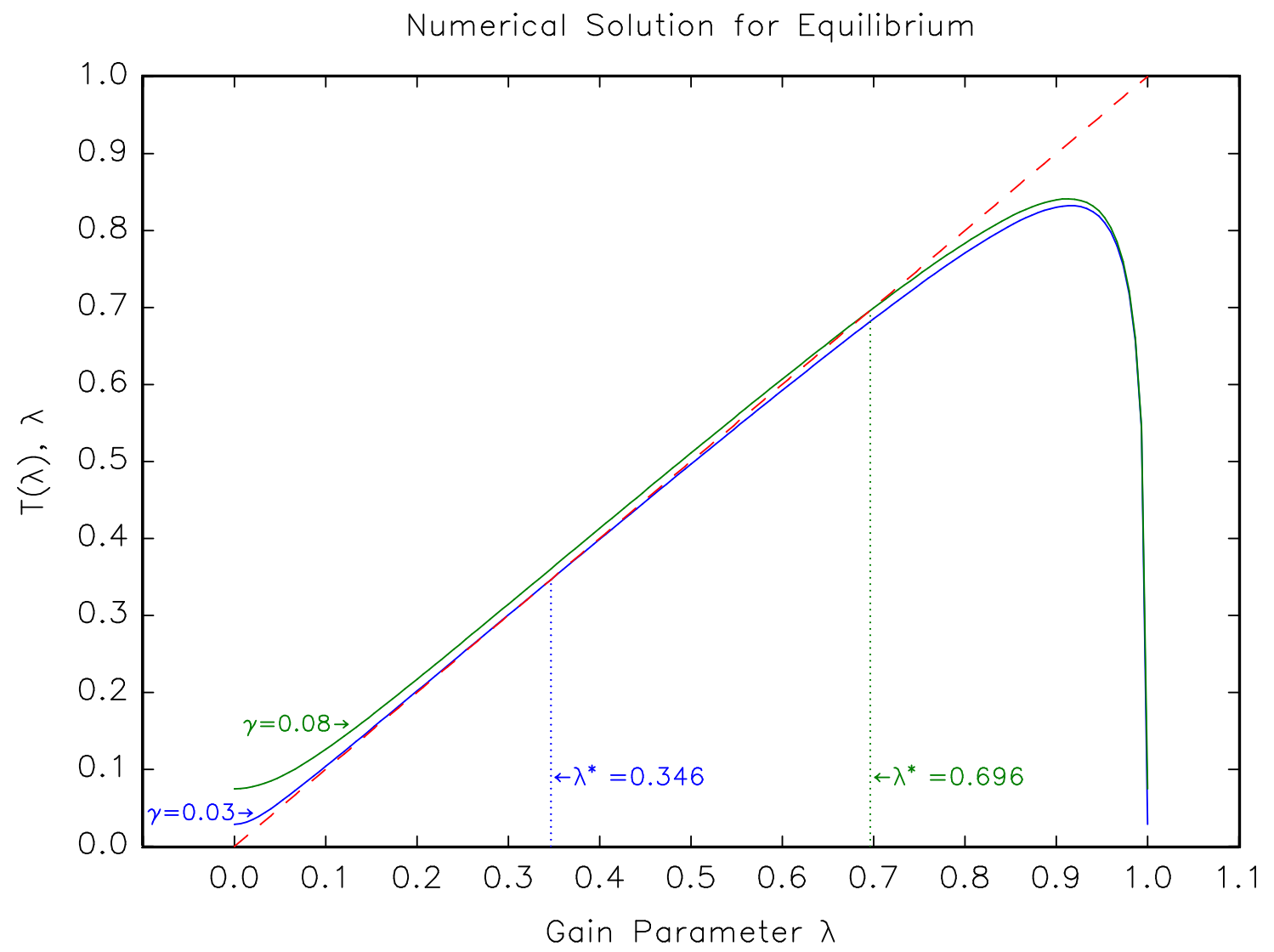

Figure 2: Determination of $\lambda^{*}$ for consistent expectations equilibrium. 
3a: Inflation Persistence

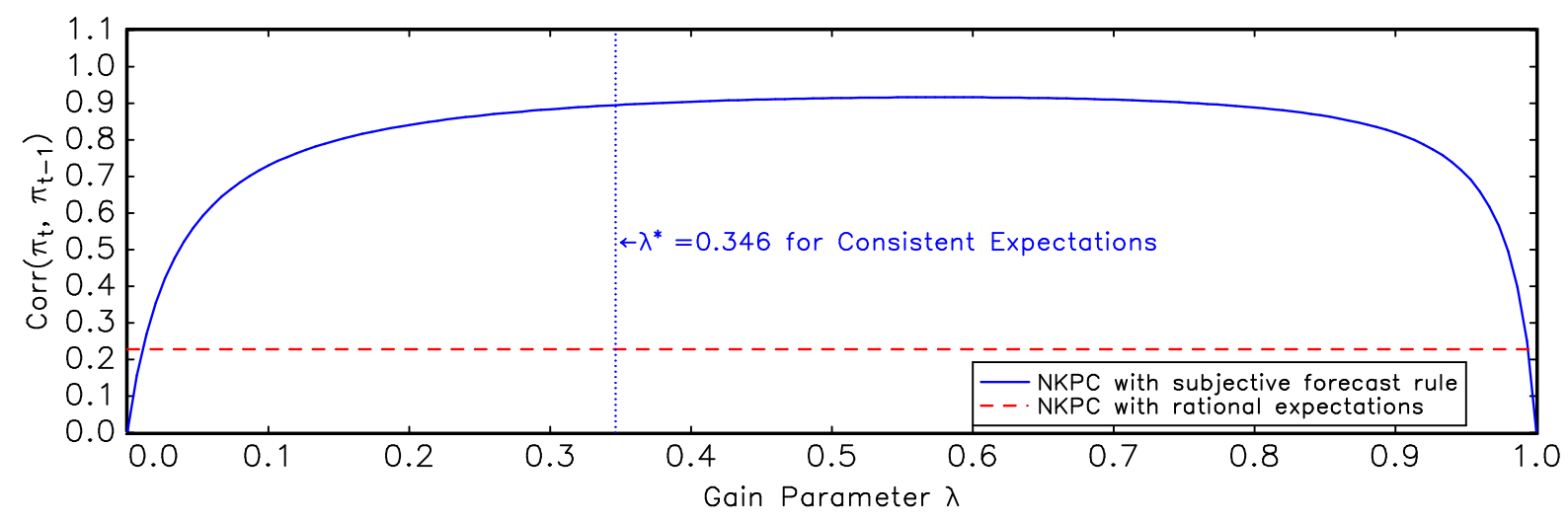

3b: Inflation Volatility

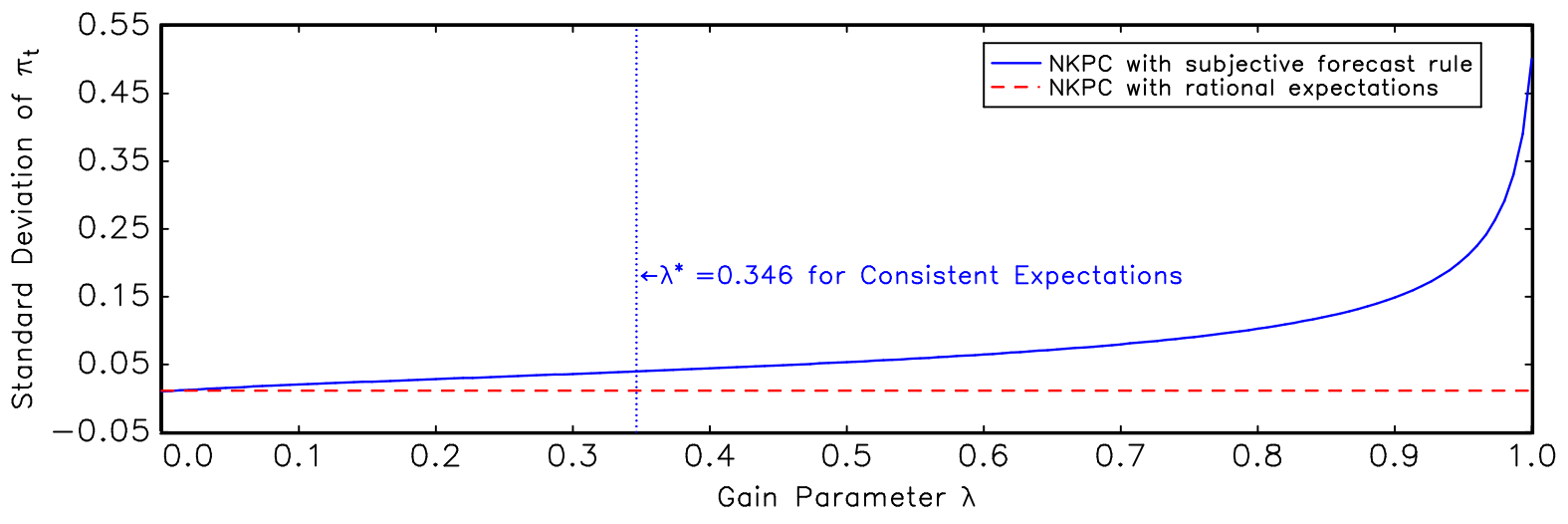

Figure 3: Effect of Kalman gain parameter on inflation persistence and volatility. 


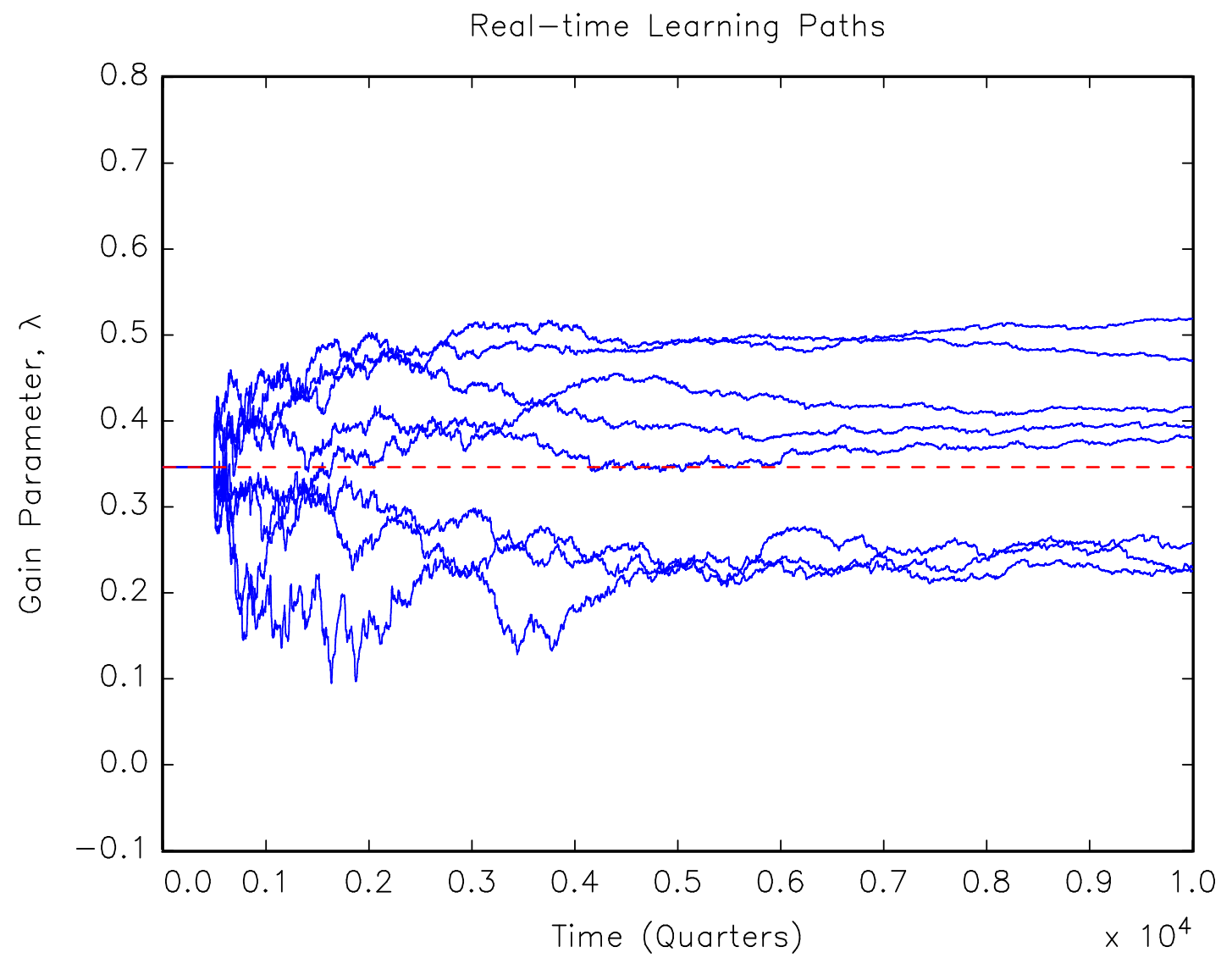

Figure 4: Sampling variation in the autocorrelation of $\Delta \pi_{t}$ affects real-time learning paths. 
5a: Autocorrelation of Changes in U.S. GDP Price Inflation

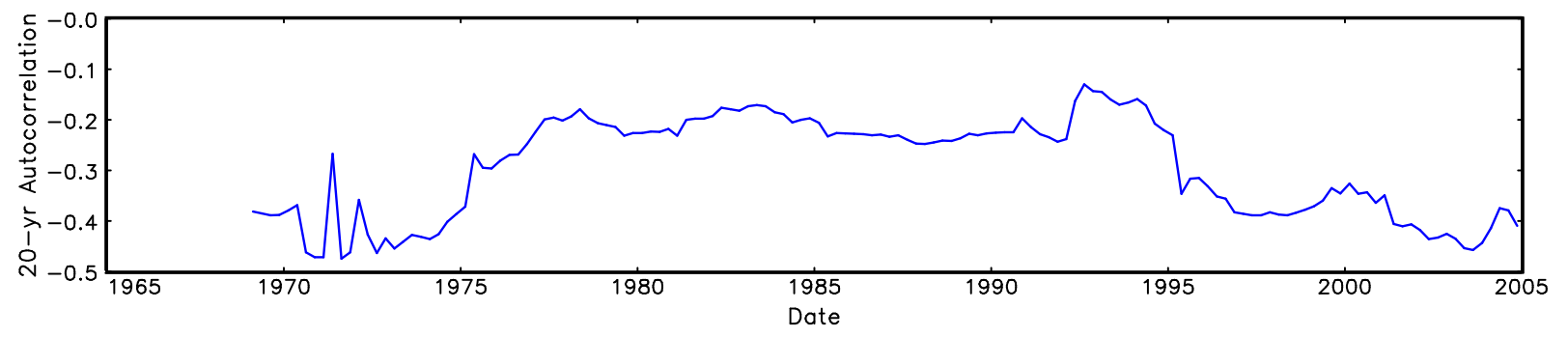

5b: Perceived Signal-to-Noise Ratio for U.S. GDP Price Inflation

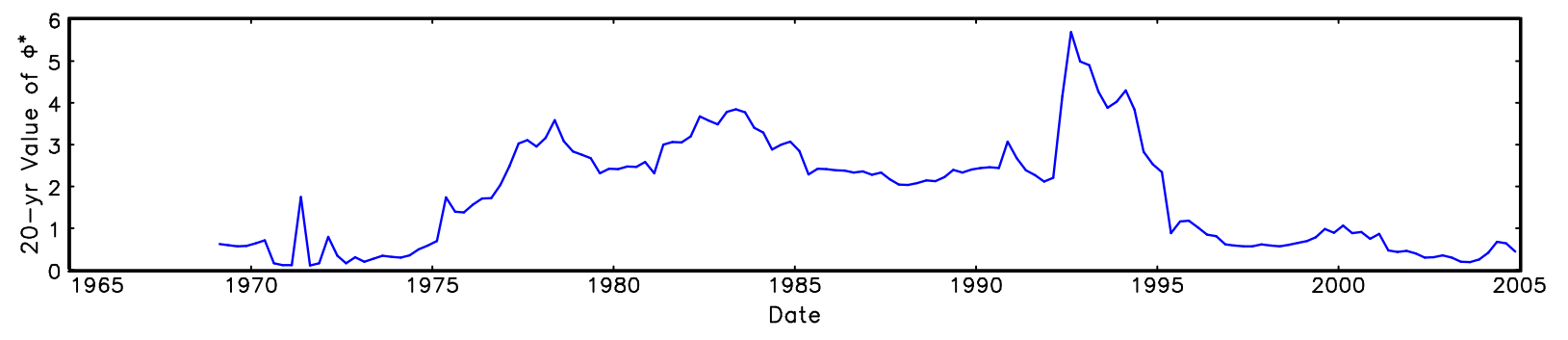

5c: Kalman Gain Parameter for U.S. GDP Price Inflation

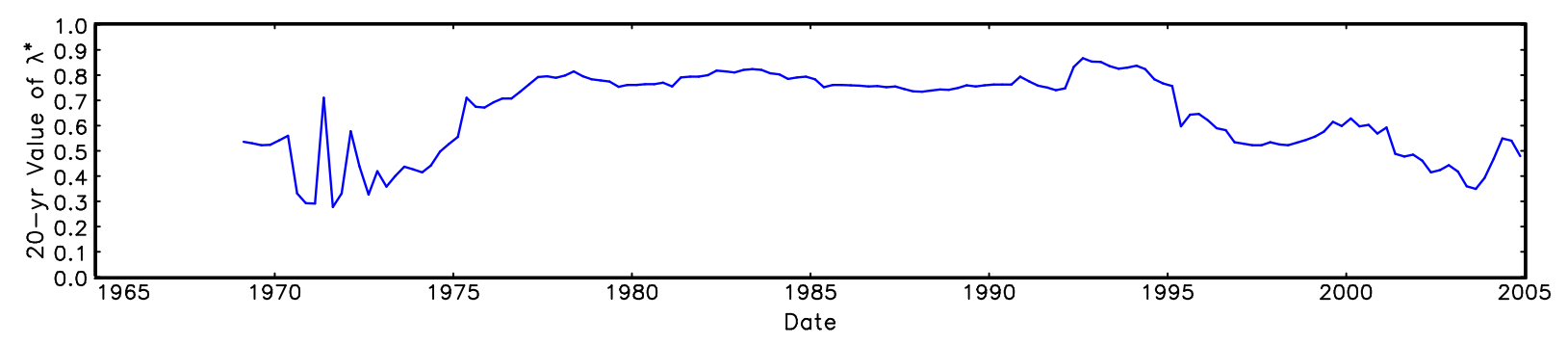

Figure 5: Identifying the signal-to-noise ratio and the Kalman gain parameter from U.S. data. 


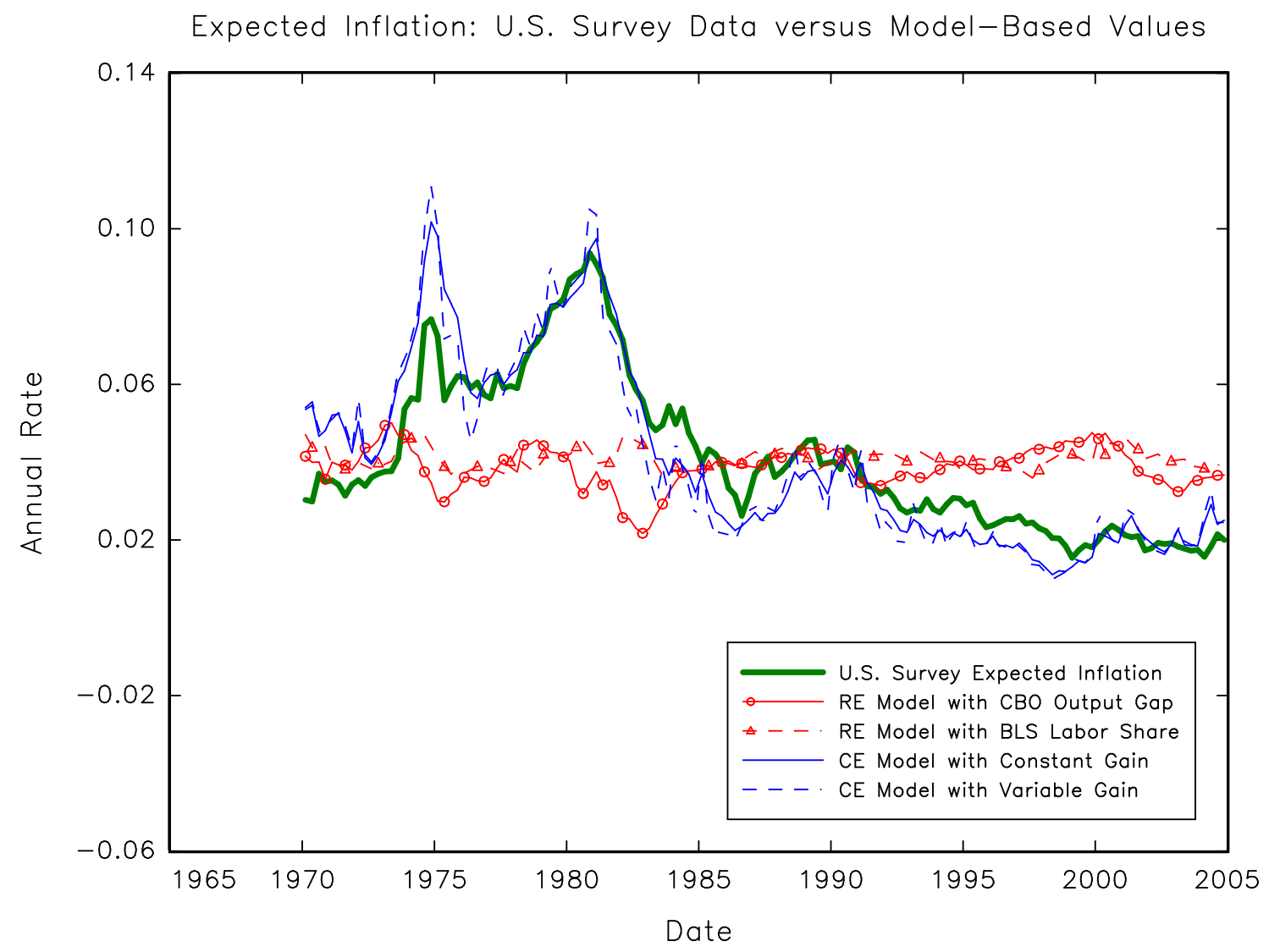

Figure 6: Comparing survey-based U.S. expected inflation to model-based values. 
7a: Forecast Fitness Measures

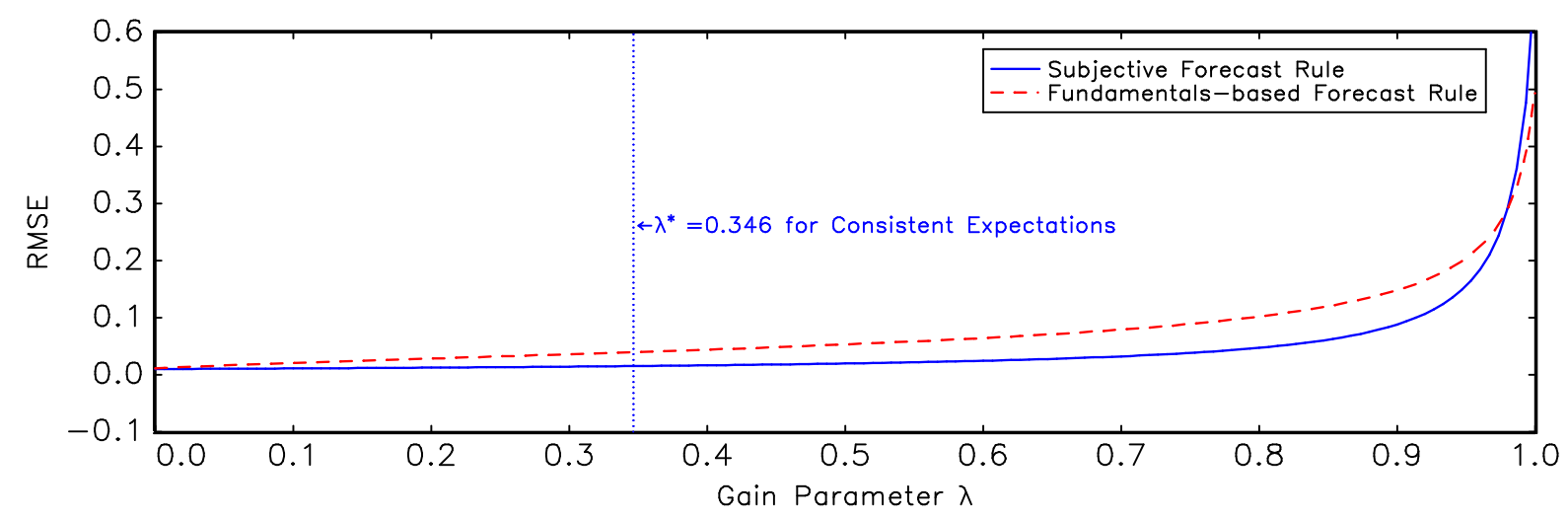

7b: Autocorrelation of Forecast Errors

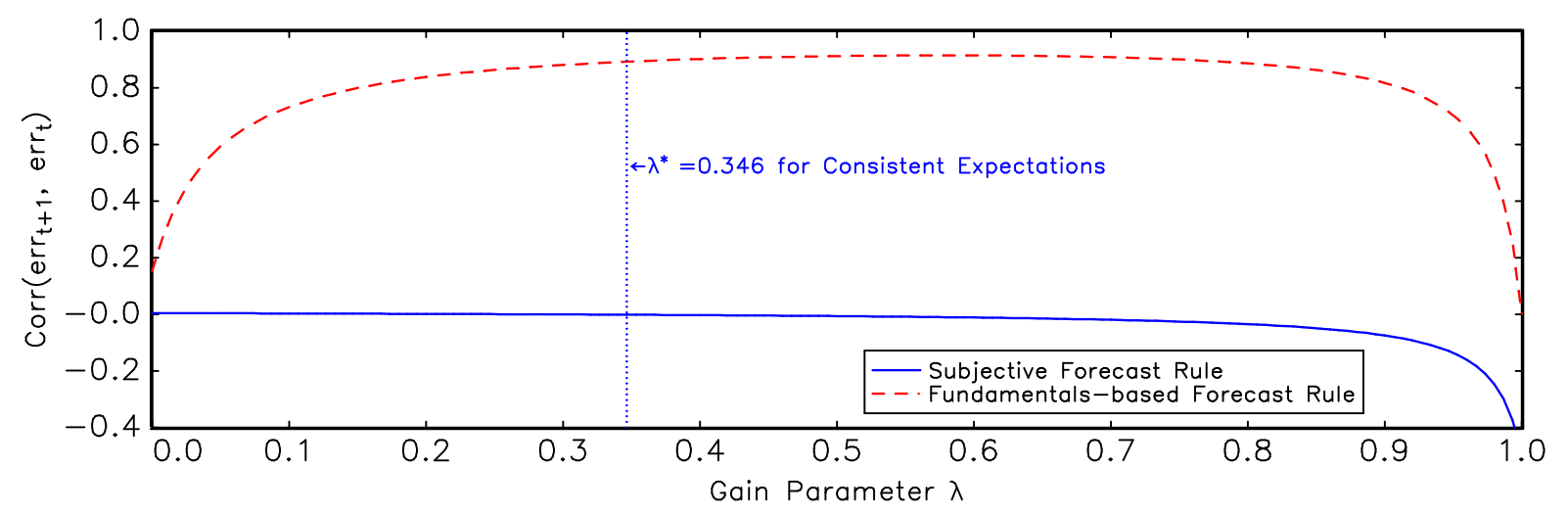

Figure 7: Properties of forecast errors when $\pi_{t}$ is generated using subjective forecast rule (9). 
8a: Inflation Rate

Rational Expectations

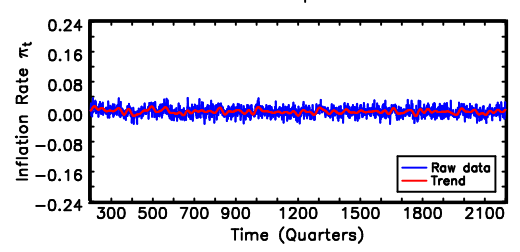

8d: Inflation Peristence

Rational Expectations

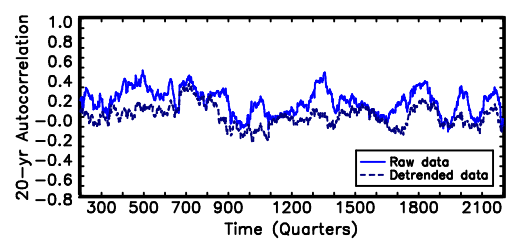

g: Inflation Volatility

Rational Expectations

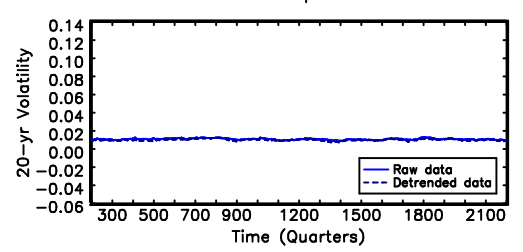

8j: Inflation Mean

Rational Expectations

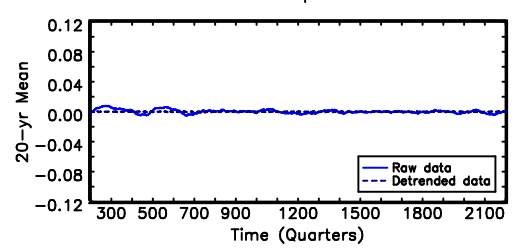

8b: Inflation Rate

Consistent Expectations, Constant Gain

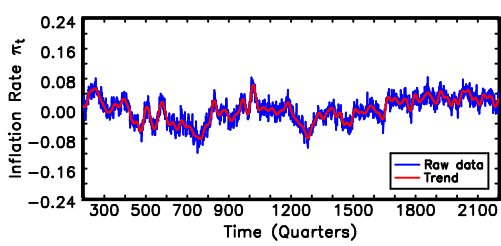

8e: Inflation Peristence

Consistent Expectations, Constant Gain

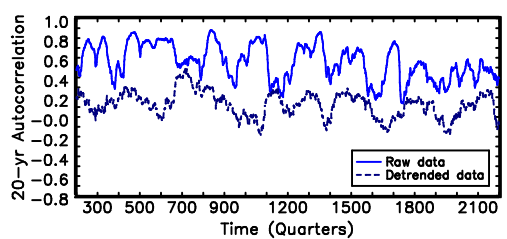

h: Inflation Volatility

Consistent Expectations, Constant Gain

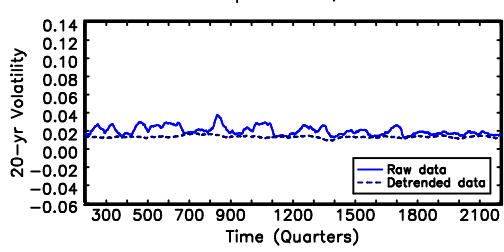

8k: Inflation Mean

Consistent Expectations, Constant Gain

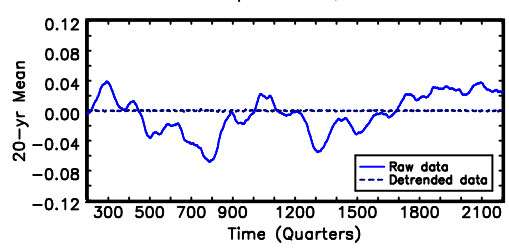

8c: Inflation Rate

Consistent Expectations, Variable Gain

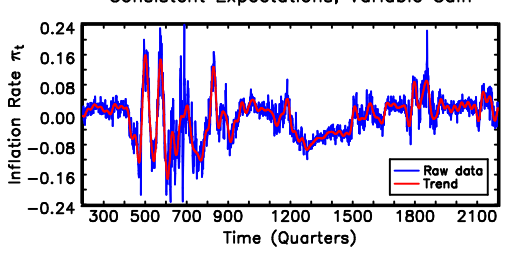

8f: Inflation Peristence

Consistent Expectotions, Voriable Gain

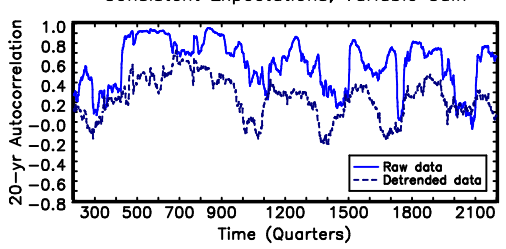

8i: Inflation Volatility

Consistent Expectations, Variable Gain

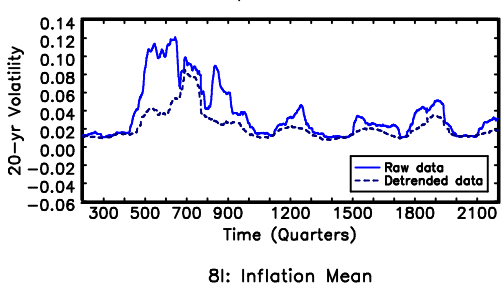

Consistent Expectations, Variable Gain

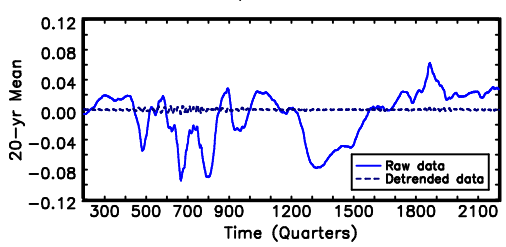

Figure 8: Simulated inflation dynamics for three different forms of expectations. 
9a: Perceived Signal-Noise Ratios

20-year Rolling Sample

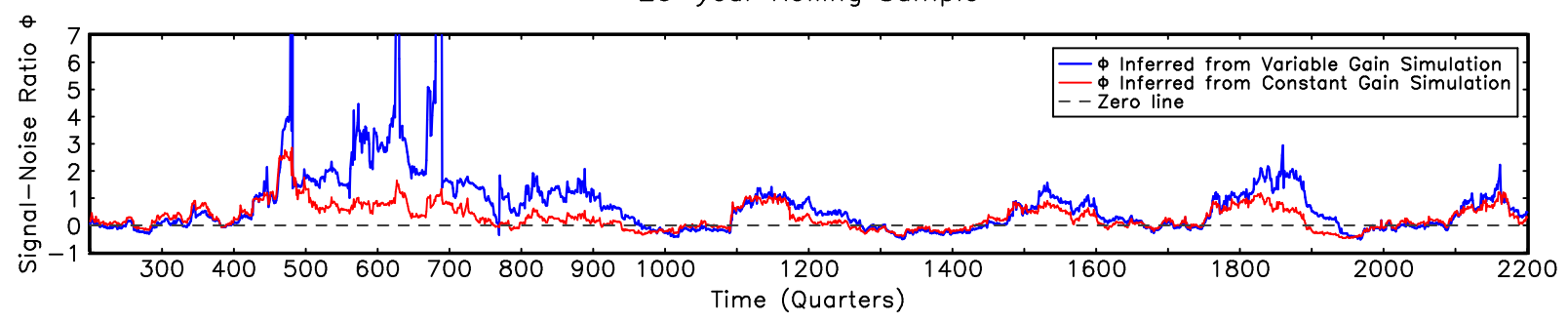

9b: Variable Gain versus Constant Gain

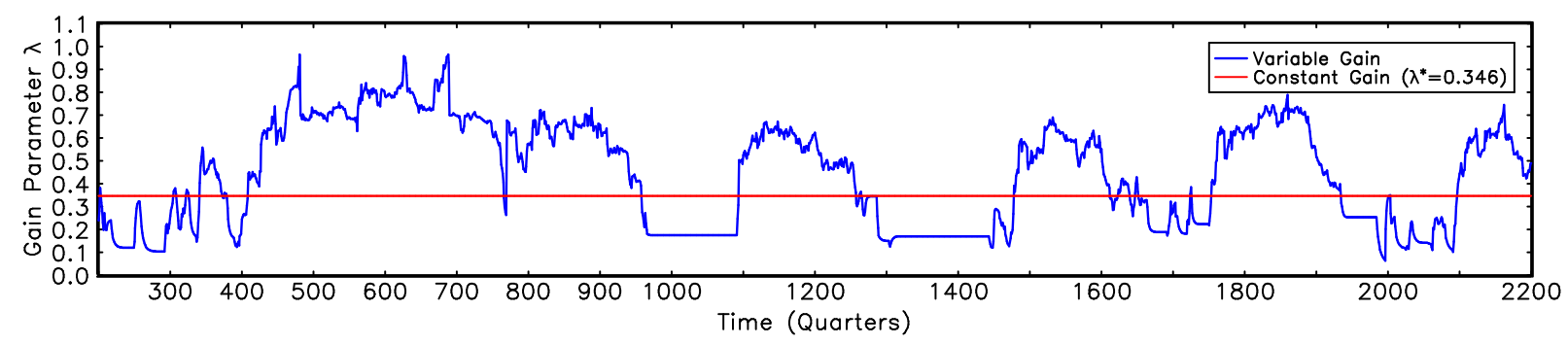

9c: Forecast Fitness Comparison

Inflation Generated Using Variable Gain Forecast

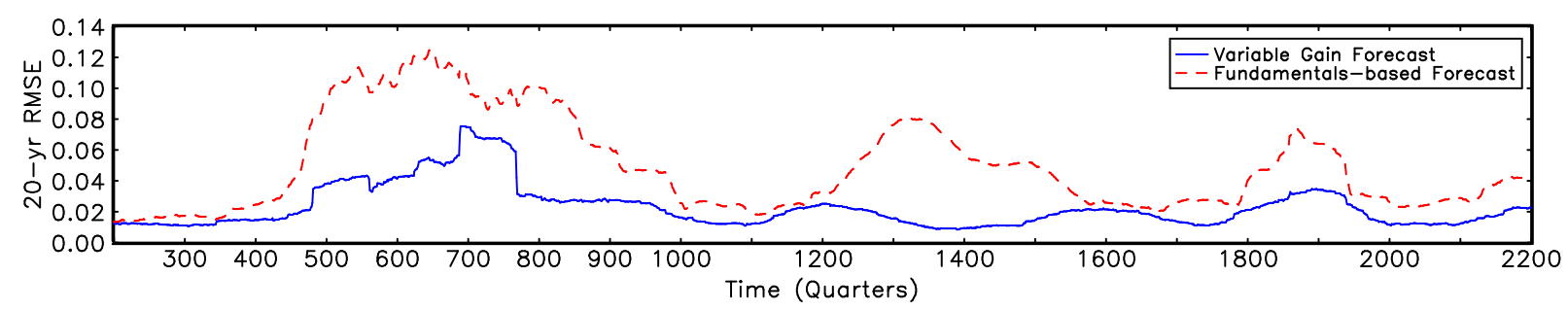

Figure 9: Additional plots for the variable-gain simulation. 